\title{
The Surface Climate Response to 11-Yr Solar Forcing during Northern Winter: Observational Analyses and Comparisons with GCM Simulations
}

\author{
LON HOOD \\ Lunar and Planetary Laboratory, The University of Arizona, Tucson, Arizona \\ SEMJON SCHIMANKE \\ Swedish Meteorological and Hydrological Institute, Norrkoping, Sweden \\ THOMAS SPANGEHL \\ German Weather Service, Offenbach am Main, Hesse, Germany \\ SOURABH BAL \\ Department of Physics, Dream Institute of Technology, Kolkata, India \\ ULRICH CUBASCH \\ Institute for Meteorology, Free University of Berlin, Berlin, Germany
}

(Manuscript received 29 November 2012, in final form 14 March 2013)

\begin{abstract}
The surface climate response to 11-yr solar forcing during northern winter is first reestimated by applying a multiple linear regression (MLR) statistical model to Hadley Centre sea level pressure (SLP) and sea surface temperature (SST) data over the 1880-2009 period. In addition to a significant positive SLP response in the North Pacific found in previous studies, a positive SST response is obtained across the midlatitude North Pacific. Negative but insignificant SLP responses are obtained in the Arctic. The derived SLP response at zero lag therefore resembles a positive phase of the Arctic Oscillation (AO). Evaluation of the SLP and SST responses as a function of phase lag indicates that the response evolves from a negative AO-like mode a few years before solar maximum to a positive AO-like mode at and following solar maximum. For comparison, a similar MLR analysis is applied to model SLP and SST data from a series of simulations using an atmosphere-ocean general circulation model with a well-resolved stratosphere. The simulations differed only in the assumed solar cycle variation of stratospheric ozone. It is found that the simulation that assumed an ozone variation estimated from satellite data produces solar SLP and SST responses that are most consistent with the observational results, especially during a selected centennial period. In particular, a positive SLP response anomaly is obtained in the northeastern Pacific and a corresponding positive SST response anomaly extends across the midlatitude North Pacific. The model response versus phase lag also evolves from a mainly negative AO-like response before solar maximum to a mainly positive AO response at and following solar maximum.
\end{abstract}

\section{Introduction}

A better knowledge and understanding of the surface climate response to $11-\mathrm{yr}$ solar forcing is needed for

Corresponding author address: Lon L. Hood, Lunar and Planetary Laboratory, The University of Arizona, 1629 E. University Blvd., Tucson, AZ 85721.

E-mail: lon@lpl.arizona.edu testing and constraining climate models that are applied on longer (e.g., centennial) time scales. From an observational standpoint, both long-term sea level pressure (SLP) and sea surface temperature (SST) data, which are available since 1850 (e.g., Allan and Ansell 2006; Rayner et al. 2006), can in principle be used to estimate the 11-yr surface climate response. Although some analyses of global SST data have yielded evidence for a detectable surface climate response, others have not, possibly 
reflecting difficulties in separating internal climate variability from solar-induced variability as well as SST data quality issues (White et al. 1997; van Loon et al. 2007; Zhou and Tung 2010; Roy and Haigh 2010; Tung and Zhou 2010; Haam and Tung 2012). However, analyses of long-term SLP data have yielded more consistent results. In particular, evidence for a positive response of SLP in the North Pacific (Aleutian region) to the solar cycle during northern winter has been obtained by a number of authors using sunspot number as a proxy for long-term solar forcing (Christoforou and Hameed 1997; van Loon et al. 2007; Roy and Haigh 2010, 2012; Hood and Soukharev 2012, hereafter referred to as HS12). Also, some analyses of SLP data have obtained a negative solar response in most of the Arctic, although it is not formally significant (e.g., HS12). This, combined with a strong positive Aleutian response, yields a pattern that resembles a positive mode of the Arctic Oscillation (AO; Thompson and Wallace 1998).

As argued, for example, by Meehl et al. (2009), model simulations of 11-yr climate responses with amplitudes comparable to those reported in observations probably require inclusion of indirect "top down" forcing via the stratosphere in addition to any "bottom up" forcing resulting from relatively small total solar irradiance (TSI) changes over a solar cycle. In its simplest form, top-down forcing consists of an enhancement of the latitudinal gradient of radiative heating in the upper stratosphere due to changes in ozone production and UV absorption (e.g., Gray et al. 2010). This perturbs the westerly zonal wind in the subtropical lower mesosphere and upper stratosphere near the times of winter solstice in each hemisphere (Kodera and Yamazaki 1990; Hood et al. 1993; Crooks and Gray 2005). The zonal wind perturbation is then amplified by wave-mean flow interactions and propagates poleward and downward in the winter hemisphere, ultimately leading to changes in tropospheric circulation (Kodera and Kuroda 2002; Haigh et al. 2005; Matthes et al. 2006). Changes in upper-stratospheric ozone production are positive near solar maxima at low to midlatitudes due in part to increased photolysis of molecular oxygen by solar UV radiation at wavelengths $<242 \mathrm{~nm}$ (e.g., Gray et al. 2010) but can be negative at polar latitudes due to downward descent of ozone-destroying odd nitrogen produced by energetic particle precipitation (e.g., Randall et al. 2009; Jackman et al. 2009; Hood and Soukharev 2006). Observational estimates of solar cycle ozone changes in the upper stratosphere, although based on only a few decades of continuous global satellite data, are several times larger than most model estimates (Soukharev and Hood 2006; Randel and Wu 2007; Gray et al. 2010).

In its simplest form, bottom-up forcing consists of a nonlinear perturbation of the Hadley and Walker circulations in the troposphere, caused by small increases in surface solar irradiance ( $\sim$ TSI) and evaporation in the cloud-poor subtropics, followed by increases in moisture transport to the tropical convergence zones, increases in wind-induced ocean currents and upwelling, increases in precipitation-induced convective heating, increases in Hadley circulation subsidence and reduced cloud production in the subtropics, and so on (Meehl et al. 2008). In addition to forcing by small $(<0.1 \%)$ intrinsic changes in TSI, perturbations of tropospheric circulation may also be produced via top-down stratospheric forcing (Haigh et al. 2005; Simpson et al. 2009), which could in turn lead to nonlinear atmosphere-ocean coupling and feedbacks. Also, modification of planetary wave amplitudes associated with the troposphere-ocean response can produce dynamical feedbacks on the lower-stratospheric response (HS12). Therefore, bottom-up and top-down forcing are not entirely independent of one another.

Consistent with the likely importance of top-down forcing, global climate models that include both a resolved stratosphere and a coupled ocean have begun to simulate the observed surface climate response to 11-yr solar forcing, including the SLP response in the Pacific sector (Meehl et al. 2009; Ineson et al. 2011; Bal et al. 2011; Misios and Schmidt 2012). Meehl et al. (2009) originally reported a simulation of relatively large SST and precipitation responses during northern winter using a full chemistry climate model [Whole Atmosphere Community Climate Model, version 3 (WACCM3)] coupled to a deep ocean model [Community Climate System Model, version 3 (CCSM3)]. This model adopted 11-yr solar spectral irradiance (SSI) variations in accordance with the proxy-based SSI model developed at the Naval Research Laboratory (NRL; Lean et al. 1995; Lean 2000; Wang et al. 2005). Results were based on one transient simulation of the fully coupled model (110 yr of model integration with 10 repeating solar cycles); composite differences between solar peak years and mean conditions were calculated for comparison to observations from van Loon et al. (2007).

Ineson et al. (2011) reported time-slice experiments (i.e., separate simulations for constant solar maximum and minimum SSI conditions) using an atmosphereocean general circulation model (GCM) with a wellresolved middle atmosphere (the Met Office Hadley Centre model). The ozone concentration in the stratosphere was held fixed at climatological levels but a relatively large solar cycle SSI change in the UV was assumed based on measurements by the Solar Irradiance Monitor (SIM) instrument onboard the Solar Radiation and Climate Experiment (SORCE) satellite (Harder et al. 2009). The latter measurements are still in the process of being validated and it has been argued that they are significantly 
affected by instrument degradation (Lean and DeLand 2012; DeLand and Cebula 2012). Nevertheless, it was found that the larger assumed UV variation produced a surface climate response during northern winter, which was similar to that seen in observations. Specifically, a negative $\mathrm{AO}$ phase and a strengthening of the Aleutian low under solar minimum conditions was obtained (see their Fig. 1), which is qualitatively consistent with observational analyses of long-term SLP data such as those summarized above.

Bal et al. (2011) reported a series of three 231-yr simulations with sinusoidal 11-yr solar forcing using an atmosphere-ocean GCM with a well-resolved stratosphere, ECHAM and the global Hamburg Ocean Primitive Equation (ECHO-G) with the Middle Atmosphere Model (EGMAM). ECHO-G in turn combines the ECHAM atmospheric GCM with a global version of the Hamburg Ocean Primitive Equation model (HOPE-G; Legutke and Voss 1999). In their simulations, the solar cycle SSI variation was moderate (again based on the NRL model for a relatively strong solar cycle), but a solar cycle variation of ozone was prescribed that differed for each of the three simulations. Composite differences (solar peak years minus solar minimum years) were then computed for comparison to observations from Meehl et al. (2009) and van Loon et al. (2007). In some cases, results showed a sea level pressure response during northern winter that was qualitatively similar to that derived from observations in the Pacific sector (see their Fig. 2). In particular, a positive mean response anomaly was obtained in the North Pacific (east of the Aleutians) under solar maximum conditions. However, the amplitude of the positive SLP response anomaly varied considerably between the different simulations and was most clearly present only during some centennial periods.

Finally, Misios and Schmidt (2012) reported an ensemble of eleven 51-yr simulations with solar cycle forcing using a different atmosphere-ocean GCM [the middle atmosphere version of ECHAM5 (MAECHAM5)]. In their simulations, which also used the NRL solar cycle SSI variation, the prescribed solar cycle ozone variation was based on previous simulations using a model with interactive chemistry, the Hamburg Model of the Neutral and Ionized Atmosphere (HAMMONIA). The HAMMONIA ozone variation (see Fig. 2 of Schmidt et al. 2010) is similar to that estimated by many two- and three-dimensional models: it has a peak amplitude of several percent near $30-35-\mathrm{km}$ altitude, declining to about $1 \%$ near the stratopause and is not strongly dependent on latitude. It was found that the ensemble mean SST response in the tropical Pacific consisted of a basinwide warming of about $0.1 \mathrm{~K}$ at solar maximum, while the SLP response was characterized by a deepening of the Aleutian low, which is not in agreement with observational analyses of long-term SLP data. The model response was therefore somewhat El Niño-like and it was argued that this could be consistent with some analyses of SST data covering only the last half of the twentieth century (White et al. 1997; Roy and Haigh 2010). However, as discussed by the authors, their model had one shortcoming in that the observed solar cycle effects in the northern winter stratosphere were poorly represented. Specifically, the polar vortex remained weak during solar maxima so there was no poleward and downward propagation of zonal wind anomalies to produce a positive AO-like tropospheric response. This was attributed to the coarse spectral resolution of the radiation scheme in MAECHAM5 together with the $\sim 1 \%$ imposed ozone change in the upper stratosphere, which resulted in a relatively weak (and slowly varying with latitude) solar cycle temperature change of $\sim 0.6 \mathrm{~K}$ in the upper stratosphere near $2 \mathrm{hPa}$. For comparison, observations indicate a maximum annual mean temperature change at this level of $\sim 1.5 \mathrm{~K}$ and a stronger dependence on latitude (Frame and Gray 2010; HS12). It was, therefore, noted that the low amplitude of the upperstratospheric temperature change over a solar cycle may have locally weakened the top-down propagation of the solar-induced dynamical signal from the upper stratosphere to the troposphere.

In this paper, we investigate further the surface climate response to 11-yr solar forcing during northern winter using both observational analyses and detailed comparisons to the GCM simulations of Bal et al. (2011). To minimize possible aliasing from the El Niño-Southern Oscillation (ENSO), which is the dominant mode of internal climate variability in the Pacific, only long-term records $(>100 \mathrm{yr})$ of SLP and SST are analyzed and a multiple linear regression (MLR) statistical model is applied that includes an ENSO term as well as a solar term. Application of the same statistical model to both observations and model results also allows a more direct comparison of the observational and model solar regression coefficients. The observational analyses differ from those reported previously by HS12 in that SST data as well as SLP data are considered to investigate the mutual consistency of the estimated 11-yr solar SLP and SST regression coefficients. The resulting observational SLP and SST solar regression coefficients are then compared to regression coefficients calculated from the GCM simulation model data in order to test whether the basic characteristics of the Pacific climate system response can be simulated in a model. The GCM simulations, which were conducted for three different assumed solar cycle variations of stratospheric ozone, also allow an investigation of the sensitivity of the results to the 
assumed ozone variation, and therefore afford at least a partial test of the importance of top-down forcing in producing the derived SLP and SST responses.

\section{Observational solar SLP and SST responses}

As reviewed above, the most consistent estimates of the surface climate response to 11-yr solar forcing have previously been obtained using SLP data, especially in the Pacific sector (e.g., van Loon et al. 2007; Roy and Haigh 2010; HS12). However, a complete description of the response ideally requires also a consideration of surface temperature, the longest and most complete records of which are available for sea surface temperature.

Zhou and Tung (2010) and Tung and Zhou (2010) have presented arguably the most detailed and complete analyses of possible solar signals in SST data to date using both the Hadley Centre's Global Ocean Surface Temperature dataset (Rayner et al. 2003), which is available since 1870, and the National Oceanic and Atmospheric Administration (NOAA) extended reconstructed SST (ERSST) dataset (Smith and Reynolds 2003, 2004; Smith et al. 2008), available since 1854. They used several statistical methods, including a composite mean difference (CMD) technique and MLR. For the CMD analysis, long-term trends present in both the SST and solar proxy time series were minimized using a pairwise differencing procedure in which the solar time series was divided into subperiods containing only one solar cycle and the maximum and minimum intervals were defined relative to the mean value for that cycle. Zhou and Tung (2010) projected the original data onto the resulting CMD pattern and showed that the projected global SST time series remained in phase with the solar cycle over the complete 150 -yr measurement record, except during a period of reduced data quality around World War II. Tung and Zhou (2010) presented detailed MLR analyses of both SST datasets to estimate the solar response as a function of season. Their results for northern winter [December-February (DJF)] show no clear El Niño-like or La Niña-like signal in the tropical eastern Pacific (see their Fig. 4). However, significant positive SST responses were obtained in local regions, including within a narrow band across the midlatitude North Pacific. Roy and Haigh (2010) also obtained a similar SST response in the North Pacific during DJF from an analysis of the NOAA dataset (see their Fig. 2a), but it was not statistically significant.

In this section, we apply the method of MLR to reestimate the mean 11-yr SLP and SST responses during the northern winter season (December, January, and February) when a statistically significant SLP response has previously been obtained using the same technique (e.g., Roy and Haigh 2010; HS12). The primary goal is to provide a quantitative basis for a more direct comparison to the EGMAM model results to be analyzed in section 3. In addition, it is of interest to investigate whether the derived SST response is physically consistent with the SLP response, especially in the Pacific sector.

The SLP and SST data analyzed here are obtained from the Met Office (http://www.metoffice.gov.uk/ hadobs). The SLP data are from the Hadley Centre SLP (HadSLP2) monthly gridded dataset (Allan and Ansell 2006), which begins in 1850 and is provided on a $5^{\circ}$ latitude-longitude grid. The SST data are from the Hadley Centre Sea Ice and SST (HadISST) monthly gridded dataset (Rayner et al. 2003), which begins in 1870 and is provided on a $1^{\circ}$ latitude-longitude grid. To analyze both SLP and SST data over a common time period and to avoid lower quality due to increased sparsity of observations prior to 1880 , only the 1880 2009 period $(130 \mathrm{yr})$ is considered here. Finally, analyses are conducted with and without including the time period around World War II (1942-50) identified by Thompson et al. (2008) and Zhou and Tung (2010) as problematic for the SST data.

The MLR model is similar to that applied previously to SLP data and stratospheric data (Hood et al. 2010; HS12) but does not include a term representative of the equatorial quasi-biennial wind oscillation $(\mathrm{QBO})$ because it was found that inclusion of one or more QBO terms does not significantly modify the calculated solar regression coefficients at sea level. The model also does not include terms representative of the Pacific decadal oscillation (PDO; Zhang et al. 1997; Mantua et al. 1997) or the AO (Thompson and Wallace 1998). This is because inclusion of these terms produces only minor changes in the observational solar coefficients and it is not straightforward to include such terms when analyzing the EGMAM model data. Specifically, the temporal behavior of a given surface climate variable $X(t)$ is represented as

$$
\begin{aligned}
X(t)= & \mu(i)+\beta_{\text {trend }} t+\beta_{\text {volcanic }} \operatorname{Aerosol}(t) \\
& +\beta_{\text {solar }} \operatorname{Solar}(t)+\beta_{\text {ENSO }} \mathrm{N} 3.4(t)+\beta_{\Delta \text { trend }} t^{\prime},
\end{aligned}
$$

where $t$ is the time in some chosen increment (e.g., months); $\mu(i)$ is the long-term mean for the $i$ th month $(i=1,2, \ldots, 12)$ or season $(i=1,2, \ldots, 4)$ of the year; $\operatorname{Aerosol}(t)$ is a stratospheric volcanic aerosol index; $\operatorname{Solar}(t)$ is an appropriate time series representative of solar irradiance or spectral irradiance; N3.4 is the Niño-3.4 index (N3.4; defined as the SST anomaly averaged over the $5^{\circ} \mathrm{S}-5^{\circ} \mathrm{N}$ and $120^{\circ}-170^{\circ} \mathrm{W}$ sector); and $t^{\prime}=0$ for $t<t_{0}$ and $t^{\prime}=t-t_{0}$ for $t \geq t_{0}$, where $t_{0}$ is a time when a change of linear trend is assumed to occur (Reinsel et al. 2005). The coefficients $\beta_{\text {trend }}, \beta_{\text {volcanic }}$, 
$\beta_{\text {solar }}, \beta_{\mathrm{ENSO}}$, and $\beta_{\Delta \text { trend }}$ are determined by least squares regression. The SST and SLP responses to ENSO forcing are assumed to occur at zero phase lag relative to N3.4. The change-of-trend term is found to be necessary when analyzing the observed SST and SLP record because the globally averaged SST time series derived from either the NOAA ERSST data or the Hadley Centre data contains a major change in slope near 1910 (see, e.g., Fig. 1 of Zhou and Tung 2010). Specifically, over the 1880-2009 period, the mean SST averaged from $60^{\circ} \mathrm{S}$ to $60^{\circ} \mathrm{N}$ first decreases following several major volcanic eruptions (e.g., Krakatau in 1883 and Santa Maria in 1902) before reversing slope in $\sim 1910$ and increasing roughly linearly thereafter. Therefore, we choose $t_{0}=$ 1910 when analyzing either SLP or SST data over this period. These observed long-term trends are likely influenced also by nonlinear greenhouse gas forcing and so are not adequately represented by a simple linear trend term plus a volcanic term. Experimental analyses with and without the change-of-trend term confirm that the derived SST solar regression coefficients are moderately modified if this term is not included.

To account for autocorrelation of the residuals (data minus statistical model), we apply a Cochrane-Orcutt transformation (Cochrane and Orcutt 1949; Tiao et al. 1990; Garny et al. 2007), in which both the modeled observations and the basis functions are adjusted to ensure that the residuals are approximately white noise. This is done in a series of steps by first determining the autoregression coefficient $\rho$ of the residuals, assuming that they can be represented as a first-order autoregressive process, and then transforming the observed time series at each grid point and all basis functions as follows: $x(t) \rightarrow x(t)-\rho x(t-1)$, where $x(t)$ is a value at time $t$ and $x(t-1)$ is the value at the previous observation time (e.g., month or season). Then, the statistical model in (1) is rerun on the transformed observed time series and basis functions. Finally, the regression coefficient variance is calculated by standard methods (e.g., von Storch and Zwiers 2002). In practice, the residual interannual variations of seasonal mean SLP and SST considered here are not strongly autocorrelated so the correction makes only a minor change in the final solar regression coefficients. Nevertheless, for completeness, we carry out this procedure.

The Aerosol $(t)$, Solar $(t)$, and N3.4(t) explanatory variable (basis function) time series adopted here are the same as those used in HS12 and are plotted in Fig. 1 over the 1850-2009 period. Specifically, the Aerosol $(t)$ time series is the logarithm to base 10 of the mean global aerosol optical depth at $550 \mathrm{~nm}$, as compiled at the Goddard Institute for Space Studies (http://data.giss. nasa.gov/modelforce/strataer). For Solar( $(t)$, we use

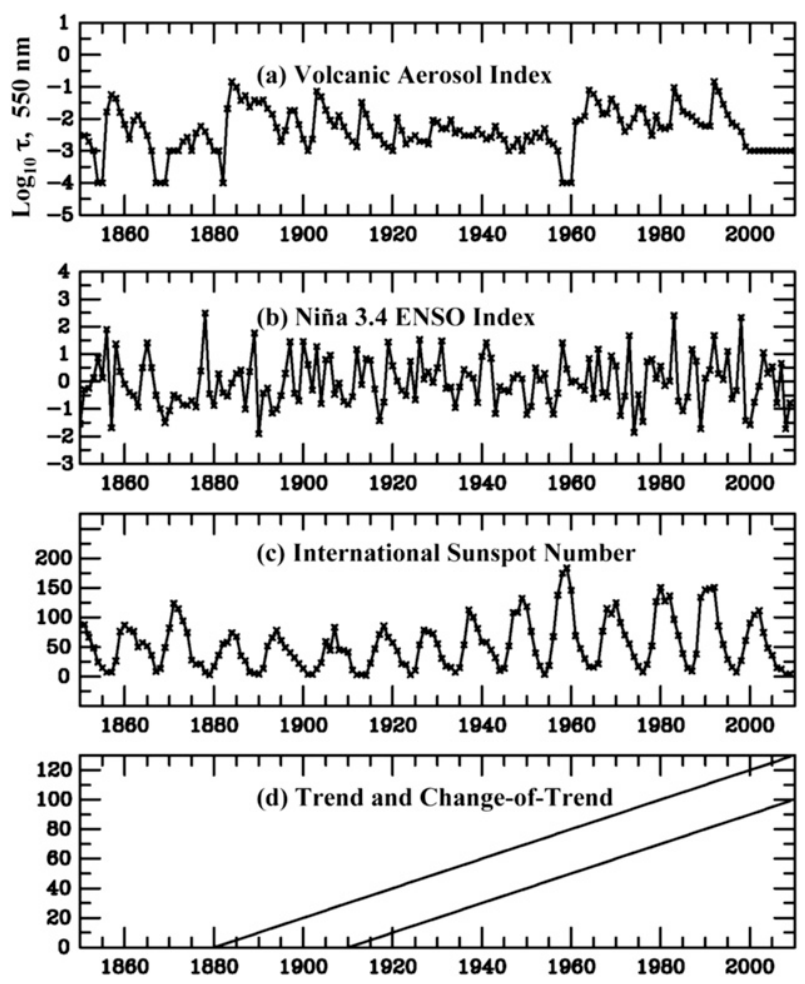

FIG. 1. Primary explanatory variables (basis functions) considered in the multiple regression statistical model. Change in (a) volcanic aerosol index, (b) Nina 3.4 ENSO index, (c) international sunspot number, and (d) trend and change-of-trend from 1850 to 2010.

sunspot number (SSN), provided by the NOAA/National Geophysical Data Center (NGDC; ftp://ftp.ngdc.noaa. gov/STP/SOLAR_DATA/SUNSPOT_NUMBERS). For N3.4 $(t)$, we use monthly mean SSTs averaged within the $5^{\circ} \mathrm{S}-5^{\circ} \mathrm{N}, 120^{\circ}-170^{\circ} \mathrm{W}$ sector using the Hadley Centre data (S. Brönnimann 2011, personal communication).

Figures 2 and 3 are intended to provide context for the discussion of the SLP and SST solar regression coefficients later in this section. Figure 2 shows the SLP and SST ENSO regression coefficients for northern winter calculated using the MLR model over the 1880-2009 period. To simplify comparisons to the solar coefficients, these ENSO coefficients are expressed as the SLP or SST change per ( -1 unit N3.4); therefore, they represent the mean SLP and SST responses to a moderate La Niña event. Although the model in (1) does not include an AO term, it is of interest to compare the SLP and SST solar regression coefficients to corresponding AO regression coefficients. For this purpose, in place of the solar term in (1), a term was added of the form, $\beta_{\mathrm{AO}} \mathrm{AO}(t)$, where $\beta_{\mathrm{AO}}$ is the regression coefficient and $\mathrm{AO}(t)$ is the Arctic Oscillation index, obtained from the NOAA/Climate Prediction Center over the 1950-2009 period (http://www.cpc.noaa.gov/products/ precip/CWlink/daily_ao_index/ao.shtml). Figure 3 plots 
(a) Hadley Centre DJF SLP Change per -1 unit N3.4, 1880-2009

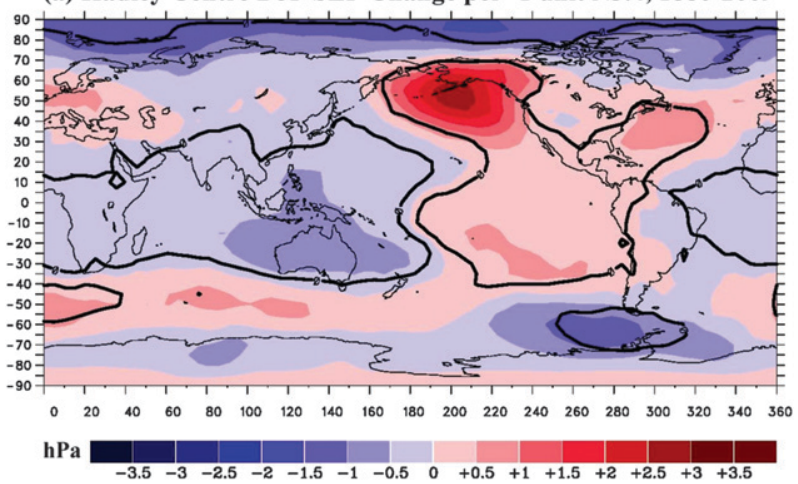

(b) Hadley Centre DJF SST Change per -1 unit N3.4, 1880-2009

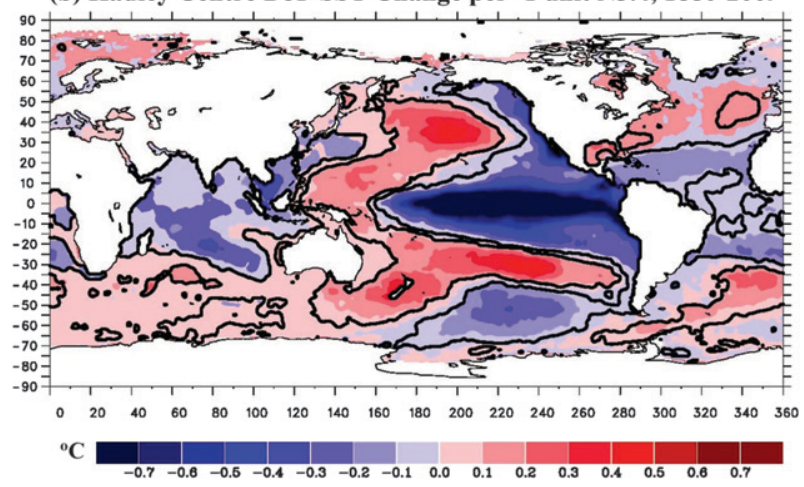

FIG. 2. (a) Mean sea level pressure and (b) sea surface temperature responses to a moderate La Niña event as estimated from a multiple regression analysis of $130 \mathrm{yr}$ of Hadley Centre data. Other independent variables included linear trend, solar, volcanic aerosol, and change of trend. Heavy dark lines enclose regions where the regression coefficients are significant at the $2 \sigma$ level.

the resulting SLP and SST AO regression coefficients calculated for this period.

As seen in Figs. 2a and 3a, the SLP responses to a cold ENSO event and a positive phase of the AO both produce a positive anomaly in the North Pacific centered on the Aleutians, representing a weakening of the Aleutian low. The corresponding SST responses shown in Figs. 2b and $3 \mathrm{~b}$ also both show a positive anomaly in the midlatitude North Pacific and a narrow negative anomaly in the northeastern Pacific extending from the Aleutians along the coast of North America. In the case of the ENSO SLP response of Fig. 2a, the positive North Pacific anomaly originates mainly from changes in convective latent heat release in the tropical central Pacific, which normally generates a Rossby wave train that follows the Pacific-North America (PNA) pattern (Wallace and Gutzler 1981; Lau et al. 1994). The weakened Aleutian low implies an anticyclonic surface wind anomaly characterized by southward flow along the northwestern American coast and easterly flow across the midlatitude North Pacific (see, e.g., Fig. 8.14a of James 1995). (a) Hadley DJF SLP Change per +1 Unit of AO Index (1950-2009)

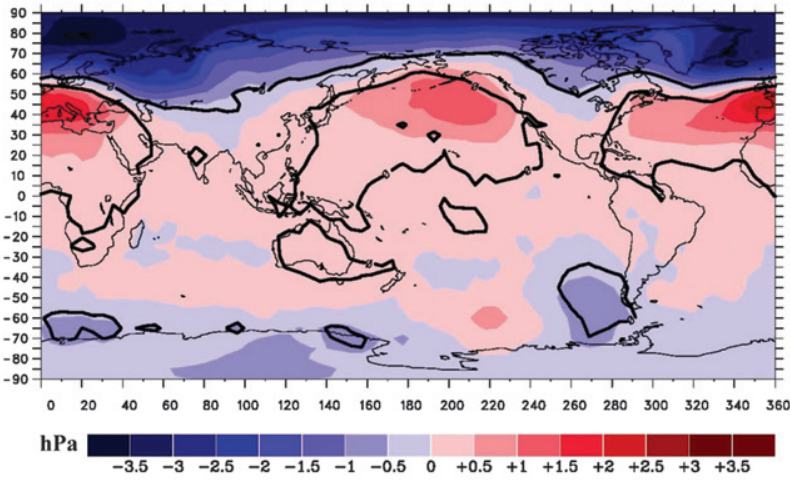

(b) Hadley DJF SST Change per +1 Unit of AO Index (1950-2009)

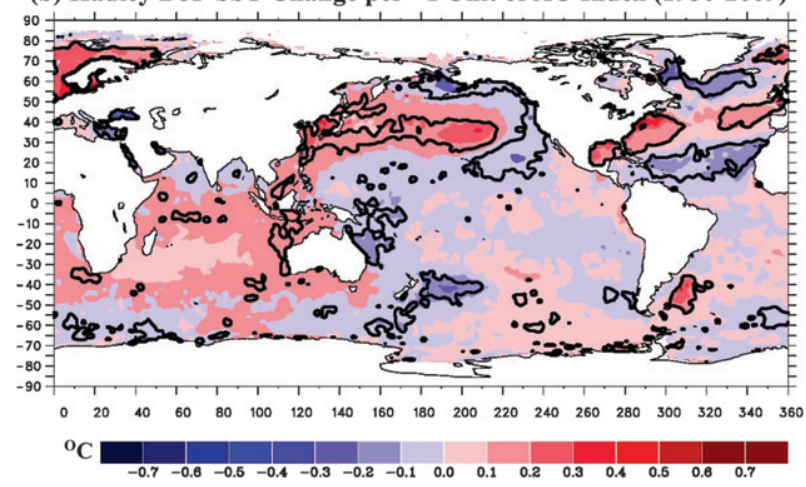

FIG. 3. As in Fig. 2, but for the responses to a positive change in the $\mathrm{AO}$ index, as estimated from a multiple regression analysis of $60 \mathrm{yr}$ of Hadley Centre data. Other independent variables included linear trend, ENSO, and volcanic aerosol.

Neglecting feedbacks from the oceanic response to first order, the anomalous easterly wind stress would tend to slow the climatological westerly North Pacific Ocean gyre current (e.g., Hartmann 1994, see his Fig. 7.7). This would in turn result in less southeastward transport of cooler surface water and a positive SST anomaly. Similarly, the anomalous southward winds along the northwestern coast would tend to enhance the southeastward California current, transporting cooler water southward along the western North American coast, producing negative SST anomalies there. In the Atlantic sector, a positive SLP response anomaly occurs east of North America and produces a stronger negative latitudinal pressure gradient between $40^{\circ}$ and $70^{\circ} \mathrm{N}$. The associated surface wind anomalies would tend to enhance the Gulf Stream and North Atlantic gyre current, transporting warmer water and producing positive SST anomalies from Florida across the North Atlantic, consistent with the observed SST response in Fig. $2 \mathrm{~b}$.

In the case of the AO response of Fig. 3, positive SLP anomalies occur across northern midlatitudes, especially over the North Pacific and Eurasian regions, coupled with strong negative Arctic anomalies. Positive SST 
anomalies occur in longitudinally extended bands across the North Pacific and North Atlantic basins. Again neglecting oceanic feedbacks onto the atmospheric response, the positive North Pacific SLP anomaly would again imply anomalous easterlies at midlatitudes, which would be consistent with the narrow band of positive SST response seen in Fig. 3b. Southward anomalous wind stresses along the northwestern American coast would again induce cold SST anomalies in the Gulf of Alaska region and along the California coast. In the European sector, a strong negative latitudinal gradient in the SLP response from Spain to the North Sea is evident, marking a positive phase of the North Atlantic Oscillation (NAO) component of the AO. The NAO index, defined as the difference in SLP between the Azores high and the Icelandic low (e.g., SLP at Lisbon, Portugal, minus that at Reykjavik, Iceland), is more strongly positive than the climatological mean during a positive phase of the AO. Under these conditions, surface winds across the midlatitude North Atlantic become more southwesterly, tending to enhance the Gulf Stream and produce warmer SSTs there. A distinct cooling of SSTs in the Labrador Sea around the southern coast of Greenland also typically occurs during a positive NAO-AO phase.

Figure 4 shows the calculated SLP and SST solar regression coefficients at zero lag over the entire 1880 2009 period. Repetitions of the SST analysis without including the period of questionable SST data around World War II noted above produce only minor changes to the results. The coefficients are expressed as the change in SLP or SST for an increase in sunspot number of 130 from solar minimum to maximum, which represents a moderately strong solar cycle (Fig. 1c). The strongest and most significant SLP response (Fig. 4a) occurs in the North Pacific, as expected from prior analyses. It has a peak amplitude of more than $3 \mathrm{hPa}$ from solar minimum to maximum. A marginally significant positive response also occurs over eastern North America while significant negative responses are centered over southcentral Asia and over the tropical Pacific. The latter includes a weakening of the climatological high between Hawaii and California. The corresponding SST response (Fig. 4b) is characterized by a series of marginally significant responses of opposite sign in the Pacific sector, including a negative response (cooling) in the eastern equatorial Pacific. In the North Pacific, a positive response is obtained across midlatitudes that is most significant on the western side and is in approximately the same region where an east-west trending response to a positive AO mode is seen in Fig. 3b. There is also a significant negative response extending from Southeast Asia to Hawaii. In the North Atlantic, a significant cooling in the Labrador Sea south of Greenland is obtained.

(a) Hadley DJF SLP Change per +130 Units of SSN (1880-2009)

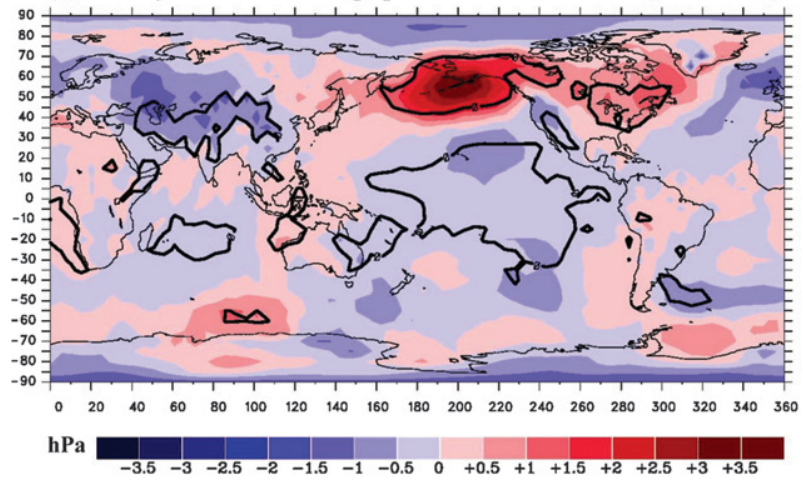

(b) Hadley DJF SST Change per +130 Units of SSN (1880-2009)

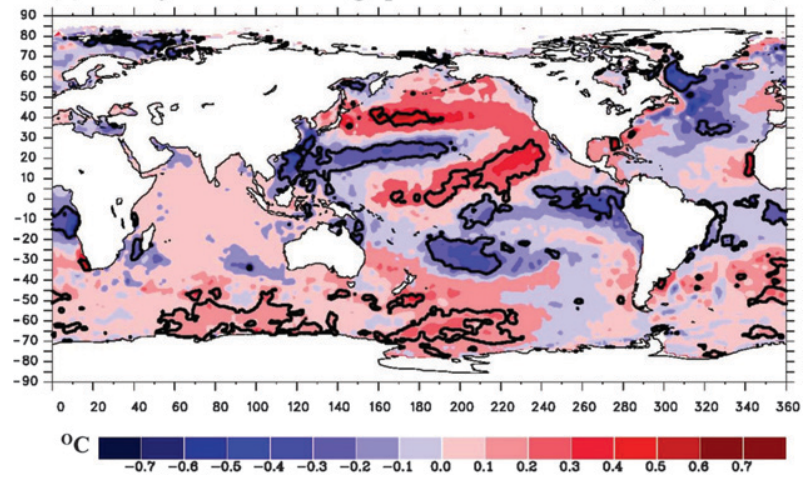

FIG. 4. As in Fig. 2, but for the SLP and SST responses to a positive change in the sunspot number of 130 at 0 -yr lag, as estimated from a multiple regression analysis of $130 \mathrm{yr}$ of Hadley Centre data.

Comparing the solar regression results of Fig. 4 to the ENSO and AO results of Figs. 2 and 3, the positive solar response is seen to be more La Niña-like than El Niñolike and more positive AO-like than negative AO-like. In particular, the positive North Pacific SLP response and the negative (but insignificant) response at Arctic latitudes seen in Fig. 4a are qualitatively similar to what are seen in Figs. 2a and 3a. The east-west trending positive SST response across the midlatitude North Pacific and the negative response south of Greenland (Fig. 4b) are also similar to the positive AO SST response in Fig. 3b. The negative SST response in the eastern tropical Pacific is La Niña-like but the latter response is much weaker than the La Niña response of Fig. 2b; also, the SST solar response structure in the North Pacific is generally more complex than the results of Figs. $2 b$ and $3 b$. There is only a weak neutral or slightly negative SST response region along the western Canadian coast in Fig. 4b. Instead, an apparently significant positive response extends across the northern subtropical eastern Pacific.

At least in the North Pacific, the solar SST response of Fig. $4 \mathrm{~b}$ is qualitatively consistent with the solar SLP response of Fig. 4a. By analogy with the interpretation 
of Figs. 2 and 3, the narrow positive solar SST response extending across the midlatitude North Pacific is a likely consequence of anomalous easterly surface winds south of the positive North Pacific SLP response anomaly. The wide longitudinal extent of the latter SLP response anomaly is consistent with this interpretation. The absence of a corresponding significant negative solar SST response along the western North American coast may be partly due to the negative solar SLP response anomaly with maximum amplitude east of Hawaii, which would imply reduced southward surface winds, a weakening of the prevailing southward California gyre current, and increased SSTs. In the Atlantic sector, the weakness and statistical insignificance of the solar SLP response (positive NAO pattern) is consistent with the absence of a significant positive band of SST response across the midlatitude North Atlantic. The cooling in the Labrador Sea region can be interpreted as a consequence of anomalous southward wind stresses along the northwest periphery of the positive SLP response anomaly centered over eastern North America.

Figures 5 and 6 show the evolution of the solar SLP and SST responses during northern winter as a function of phase lag from -2 to $+2 \mathrm{yr}$ relative to mean solar maximum. To produce these plots, the SSN time series was shifted at 1-yr increments and the regression analysis was repeated. For example, to obtain the response at a lag of $-2 \mathrm{yr}$ ( $2 \mathrm{yr}$ prior to solar maximum), the SSN series is shifted 2 yr earlier in time. As seen in Fig. 5a, the solar SLP response during DJF 2 yr prior to solar maximum is more negative AO-like with positive but insignificant responses at high (Arctic) latitudes. The NAO index (difference in SLP between the Azorean high and the Icelandic low) is also decidedly negative. The North Pacific SLP response reaches maximum amplitude and significance at zero lag as the sign of the Arctic response becomes negative (Fig. 4a). Two years after solar maximum (Fig. 5d) the SLP response remains positive AO-like with a strong negative response anomaly over the Siberian Arctic and a positive NAO index. A strong positive SLP response anomaly is present across the North Atlantic at this phase lag, which is similar to that obtained during a positive AO phase or during a La Niña event. Thus, overall, the boreal winter solar SLP response appears to evolve from negative AO-like several years before solar maxima on average to positive AO-like at and following solar maxima.

The evolution with phase lag of the boreal winter solar SST response in Fig. 6 is generally consistent with the SLP response evolution in Fig. 5. In the North Pacific, as the Aleutian positive SLP response strengthens 1 year prior to solar maximum (Fig. 6b), the regional SST responses also strengthen with a positive anomaly over (a) DJF SLP Change per 130 Units of SSN, Lag $=-2$ Years

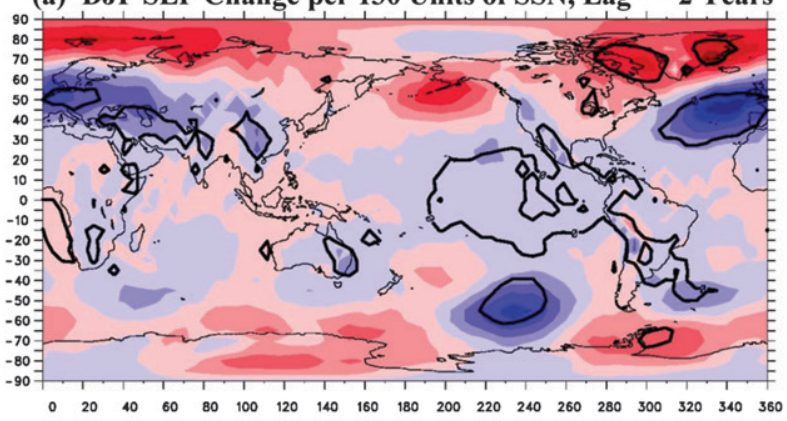

(b) DJF SLP Change per 130 Units of SSN, Lag $=-1$ Year

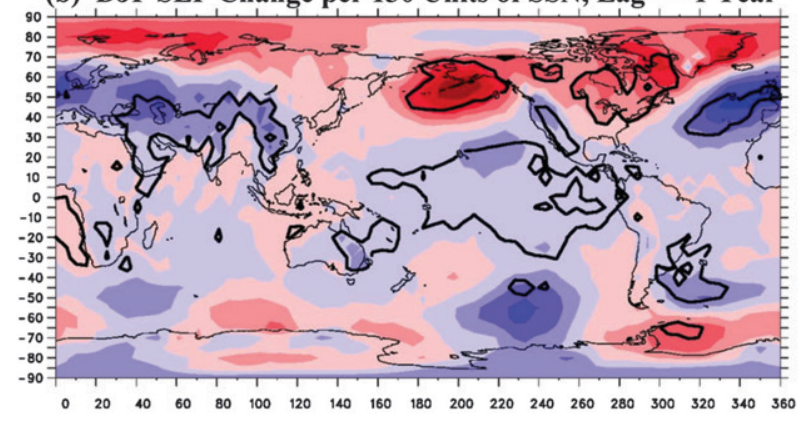

(c) DJF SLP Change per 130 Units of SSN, Lag $=+1$ Year

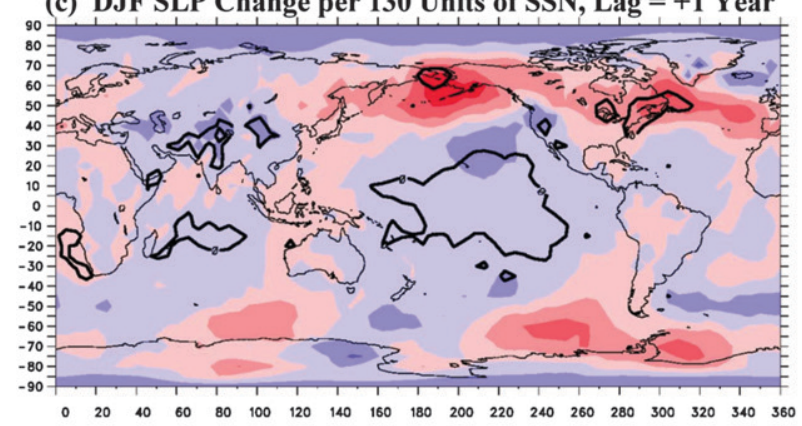

(d) DJF SLP Change per 130 Units of SSN, Lag $=+2$ Years

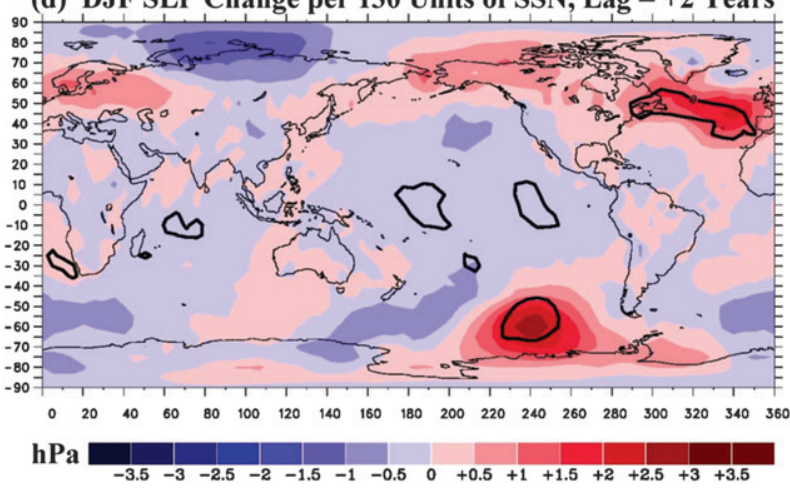

FIG. 5. The Hadley Centre sea level pressure response to a change in SSN of +130 as a function of phase lag (format as in Fig. 4a): (a) 2 and (b) 1 yr before solar maximum; and (c) 1 and (d) 2 yr after solar maximum. 
(a) DJF SST Change per 130 Units of SSN, Lag = -2 Years

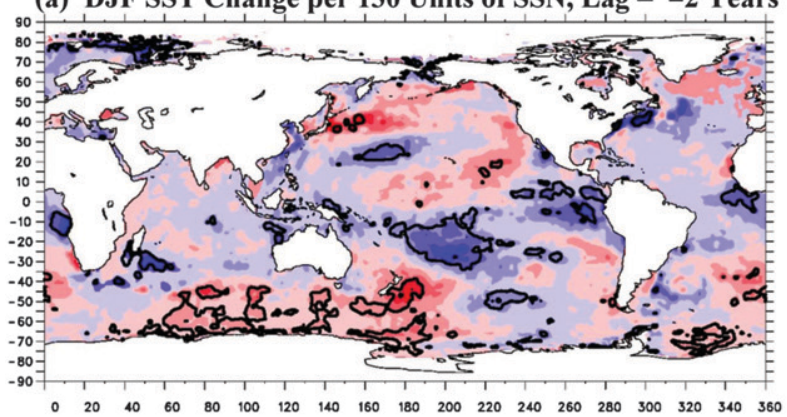

(b) DJF SST Change per 130 Units of SSN, Lag $=-1$ Year

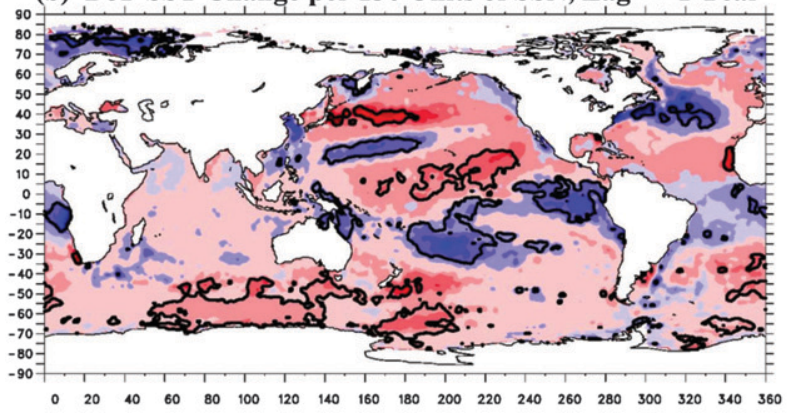

(c) DJF SST Change per 130 Units of SSN, Lag $=+1$ Year

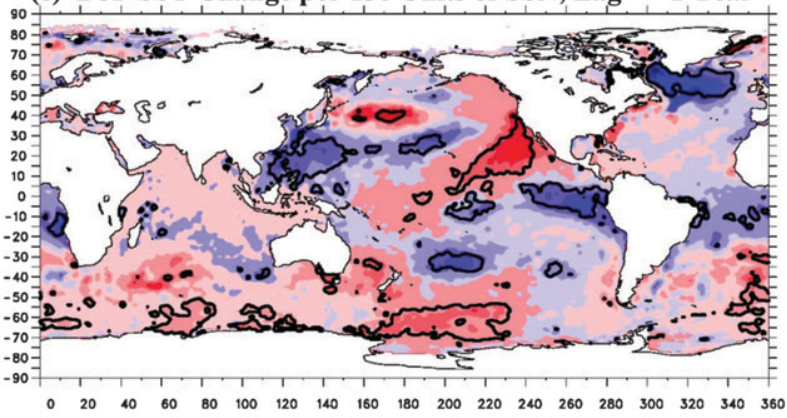

(d) DJF SST Change per 130 Units of SSN, Lag = +2 Years

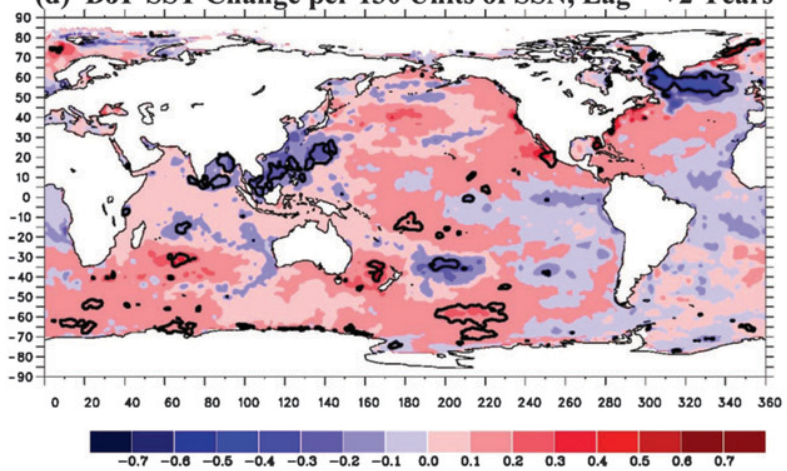

FIG. 6. As in Fig. 5, but for the sea surface temperature response.

the midlatitude western Pacific and a parallel negative anomaly south of this. At this phase lag, a narrow negative (but insignificant) response is obtained along the western North American coast that is similar to that obtained during a positive AO event (Fig. 3b). The weak La Niña-like negative SST response in the eastern equatorial Pacific also strengthens and reaches maximum amplitude at zero lag (Fig. 4b) before becoming insignificant at a lag of $+2 \mathrm{yr}$ (Fig. 6d). Two years before solar maximum (Fig. 6a), the SST response in the Labrador Sea is positive and insignificant but becomes negative at solar maximum (Fig. 4b). It is most well developed 1 or $2 \mathrm{yr}$ after solar maximum (Figs. 6c,d) during the period when a positive NAO-like SLP response is obtained.

\section{EGMAM solar SLP and SST responses}

The observational results of the previous section suggest that 11-yr solar SLP and SST responses during boreal winter are detectable and may be physically consistent with one another, especially in the North Pacific and North Atlantic regions. Results also suggest that the SLP and SST responses are strongest and most statistically significant near zero phase lag (at mean solar maximum or minimum), but that the response evolves from being somewhat negative AO-like a few years prior to solar maximum to being positive AO-like at and up to a few years after solar maximum. Although a fairly long and carefully constructed SLP and SST record has been analyzed ( $130 \mathrm{yr}$ of Hadley Centre data) and although an MLR model including an ENSO term was applied, one must always consider the possibility that a chance alignment of ENSO episodes with the solar cycle during the measurement record has contributed to the observational results (see, e.g., Haam and Tung 2012). The evolution of the solar SLP and SST responses with phase lag on a time scale of years seen in Figs. 5 and 6 might suggest the influence of such a chance alignment, since the time scale of ENSO events is 3-7yr. On the other hand, it is also possible that a physical phase locking between ENSO type variability, the 11-yr solar cycle, and decadal variations of the atmosphere-ocean system can explain such a temporal evolution (White and Liu 2008). To test further whether the observed solar SLP and SST responses are indeed a consequence of 11-yr solar forcing and whether the evolution with phase lag is real, it is therefore necessary to investigate whether the derived response characteristics can be approximately simulated in an appropriate climate model.

In this section, for the purpose of carrying out such an investigation, we consider a series of simulations using an atmosphere-ocean GCM with a well-resolved stratosphere that was originally reported by $\mathrm{Bal}$ et al. (2011). As described by the authors, the model consists of a fully coupled atmosphere-ocean GCM, EGMAM (Legutke and Voss 1999; Manzini and McFarlane 1998). The particular model version that was used has a high top $(0.01 \mathrm{hPa}$ or $\sim 80 \mathrm{~km})$ and included a highly resolved 
spectral radiation scheme at UV and visible wavelengths [Free University of Berlin (FUB) high-resolution radiation scheme (FUBRad); Nissen et al. 2007]. The atmospheric model component of EGMAM (MA-ECHAM4) has T30 horizontal and L39 vertical resolution. The coupled ocean model component has 21 vertical levels and a horizontal resolution of $2.8^{\circ}$. The model did not simulate a QBO and had mainly weak easterly winds in the tropical lower stratosphere. The model did, however, simulate a realistic ENSO (see below) with a peak periodicity of about $2 \mathrm{yr}$.

As also described by Bal et al. (2011), the EGMAM simulations assumed a sinusoidal solar forcing function with a period of $11 \mathrm{yr}$ and with time-dependent changes in solar spectral irradiance prescribed using the proxybased NRL model of Lean (2000). The assumed TSI variation was $\pm 1.25 \mathrm{~W} \mathrm{~m}^{-2}$, which is about twice the observed amplitude. The SSI variations were scaled to observed changes in the $10.7 \mathrm{~cm}$ solar radio flux (F10.7) with minimum and maximum values assumed to be 70 and 270 solar flux units, respectively. Since the EGMAM GCM does not include interactive chemistry, a prescribed solar cycle ozone variation was applied to account approximately for the photochemical component of solar radiative forcing. Specifically, assumed ozone percent changes were applied to a background, seasonally varying ozone climatology (Fortuin and Langematz 1994) using the same sinusoidal forcing function that was employed for the SSI variation.

Three different simulations of 21 solar cycles each (231 yr), denoted S1, S2, and S3, were run employing three different assumed ozone solar cycle variations: 1) a solar cycle variation computed at all latitudes using a 2D radiative-photochemical model (Haigh 1996); 2) a solar cycle variation estimated observationally at latitudes $<60^{\circ}$ from MLR analyses of long-term satellite ozone data (Soukharev and Hood 2006; Hood et al. 2010), tapered linearly to zero at the poles; and 3) a solar cycle variation as in 2) but substituting the calculated $2 \mathrm{D}$ model variation at latitudes $>60^{\circ}$. The observed solar cycle variation was only applied at latitudes $<60^{\circ}$ because the long-term satellite datasets that were analyzed (based on backscattered ultraviolet or solar occultation measurements) do not extend to higher latitudes in the winter hemisphere. Simulation S1 also differed from simulations $\mathrm{S} 2$ and $\mathrm{S} 3$ in that the $2 \mathrm{D}$ model ozone variation included an annual cycle whereas the observationbased ozone variations used annual mean solar regression coefficients with no annual cycle. However, the annual cycle of the $2 \mathrm{D}$ ozone solar cycle variation was not very large compared to that of the ozone climatology.

Figure 7 is a graphical representation of the three different ozone percent variations from solar minimum to maximum that were used as a function of latitude and pressure level. Note that linear interpolation was applied between $60^{\circ}$ and $65^{\circ}$ latitude in Fig. $7 \mathrm{c}$ to minimize any discontinuities between the two prescribed ozone variations. The assumed ozone solar cycle variations in Fig. 7 are sufficiently different from one another to afford a significant test of the importance of stratospheric processes (top-down forcing) in producing the model surface climate responses. Although all three simulations included the same solar cycle SSI variations and, hence, would produce a solar cycle variation of radiative heating in the upper stratosphere, the change in ozone also results in a comparable contribution to the radiative heating change (Gray et al. 2009, see their Fig. 2). As seen in Fig. 7a, the 2D model ozone change near $1 \mathrm{hPa}$ is about $1 \%$ and does not vary significantly with latitude. The same is true for the composite model in Fig. 7c at latitudes higher than $65^{\circ}$. This small ozone variation would produce a radiative heating change that is much smaller than that due to the SSI change. However, the observationally estimated ozone changes are as large as $4 \%$ and decrease rapidly with latitude between $60^{\circ} \mathrm{N}$ and the pole. Therefore, the ozone variation in Fig. $7 b$ and, to a lesser extent that in Fig. 7c, should produce substantially stronger upper-stratospheric radiative heating and zonal wind perturbations than the ozone variation in Fig. 7a.

Monthly EGMAM SLP and SST model data for each of the three simulations were provided on a grid with a regular $3.75^{\circ}$ longitude spacing and an irregular latitude spacing ranging from $\sim 3.71^{\circ}$ at the equator to $\sim 3.68^{\circ}$ near the poles. All model data were first interpolated to a $5^{\circ}$ longitude by $5^{\circ}$ latitude grid (same as the Hadley SLP data). Each simulation was assumed to commence in model year 1 and to continue through model year 231 . For each simulation, a model N3.4 basis function time series was first constructed by averaging the model SST data within the N3.4 region in the central equatorial Pacific. A sinusoidal model F10.7 basis function time series was also constructed with the first solar minimum at 70 solar flux units (sfu) in model year -3 , the next solar maximum at 270 sfu in model year 3, the next minimum in model year 8 , and so on. Prior to MLR analysis, the first 55 years ( 5 solar cycles) of each simulation were discarded to minimize spinup effects. The remaining model data (176yr or 16 cycles for each simulation) were then analyzed using the MLR model in (1) but without including the volcanic and change-oftrend terms. The latter terms were unnecessary since no volcanic forcing was applied in the simulations and no more than a quasi-linear trend was present in the model SST time series. In addition to MLR analyses of each simulation, a final MLR analysis of the ensemble time 
(a) $\mathrm{O}_{3}$ Change from 2D Model (Haigh 1994)

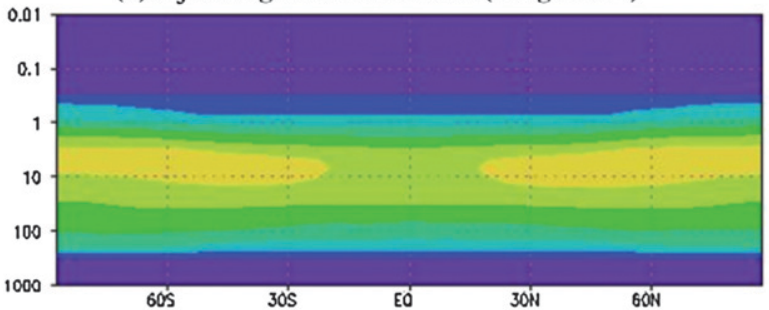

(b) $\mathrm{O}_{3}$ Change from Observations (Soukharev \& Hood 2006)

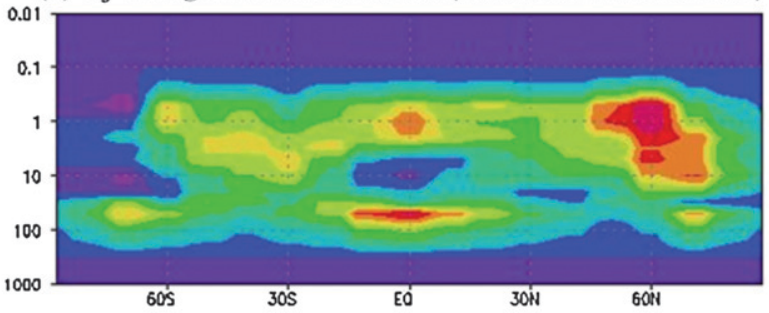

(c) $\mathrm{O}_{3}$ Change from Observations $+2 \mathrm{D}$ Model

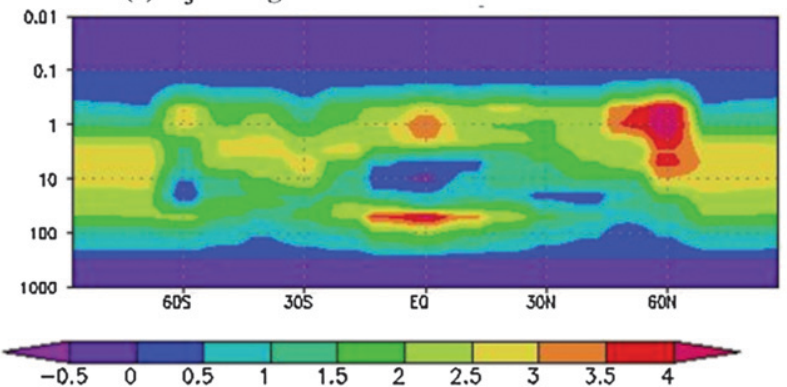

FIG. 7. Annual mean ozone percent change from solar minimum to maximum specified in (a)-(c) each of the three EGMAM simulations as a function of latitude and pressure level $(\mathrm{hPa})$. See the text.

series (S1, S2, and S3 added in series for a total of $176 \times$ 3 yr) was also carried out.

Figure 8 shows the northern winter ENSO SLP and SST regression coefficients calculated from the ensemble model data plotted in the same format as the observational results shown in Fig. 2. Note that the SST coefficients shown in Fig. $8 \mathrm{~b}$ are on an interpolated $5^{\circ}$ grid so some areas near the continents have missing data. Also, no coefficients are plotted north of $75^{\circ} \mathrm{N}$ to avoid areas occupied by sea ice. In general, the model ENSO results shown in Fig. 8 are very consistent with the observational results shown in Fig. 2. The positive North Pacific SLP response [hPa per ( -1 unit N3.4)] is slightly stronger than that obtained in Fig. 2a and is displaced somewhat to the southeast (centered at about $40^{\circ} \mathrm{N}$, $145^{\circ} \mathrm{W}$ ). The positive SST response anomaly in the North Pacific corresponds well with that seen in Fig. $2 b$ but is more extended to the west. The negative response along the west coast of North America is also simulated. In the North Atlantic, a positive SST response similar to that in (a) EGMAM DJF SLP Change per -1 unit N3.4, $176 \times 3$ years

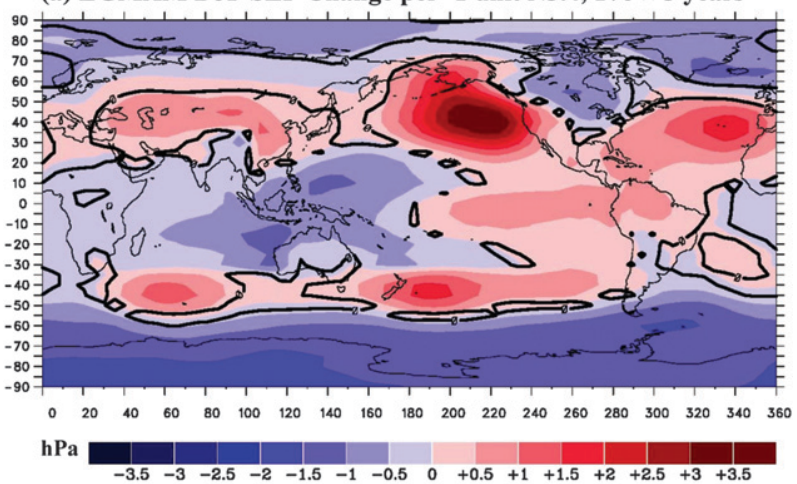

(b) EGMAM DJF SST Change per -1 unit N3.4, $176 \times 3$ years

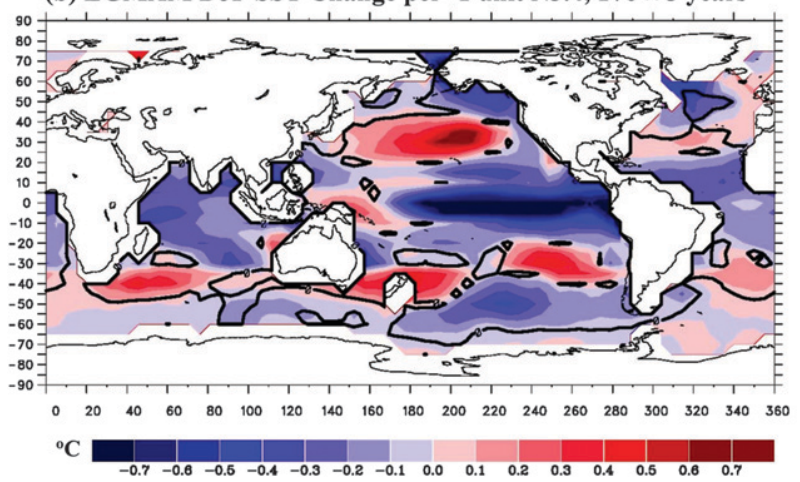

FIG. 8. Northern winter (a) mean sea level pressure and (b) sea surface temperature responses to a moderate La Niña event as estimated from a multiple regression analysis of three EGMAM simulations combined in series $(176 \times 3 \mathrm{yr})$.

Fig. $2 \mathrm{~b}$ is present, but a more distinct negative response is present in the Labrador Sea region. A stronger positive SLP NAO is present in Fig. 8a than in Fig. 2a. Finally, the cold tongue response in the eastern equatorial Pacific is well simulated in Fig. 8b, but is somewhat narrower in latitudinal extent than the observational result in Fig. $2 b$.

The solar SLP and SST regression coefficients derived from the EGMAM model data are plotted (see Figs. 1013) in units of SLP or SST change per 130 units of model F10.7. This allows a reasonable direct comparison to the observational results of Figs. 5-7 (given in units of SLP or SST change per 130 units of SSN) because an increase of 130 units of F10.7 over a solar cycle is approximately equivalent to a change of 130 units of SSN. That this is true is indicated in Fig. 9, which is a scatterplot of monthly mean observed F10.7 (obtained from the NOAA NGDC) versus monthly mean SSN over the 1948-2010 period. For example, an increase in F10.7 from 80 to 210 sfu (within the 70-270-sfu range assumed in the simulations) corresponds approximately to an increase in sunspot number from about 20 to 150 .

Figures 10,11, and 12 show the model solar SLP and SST regression coefficients at zero phase lag relative to 


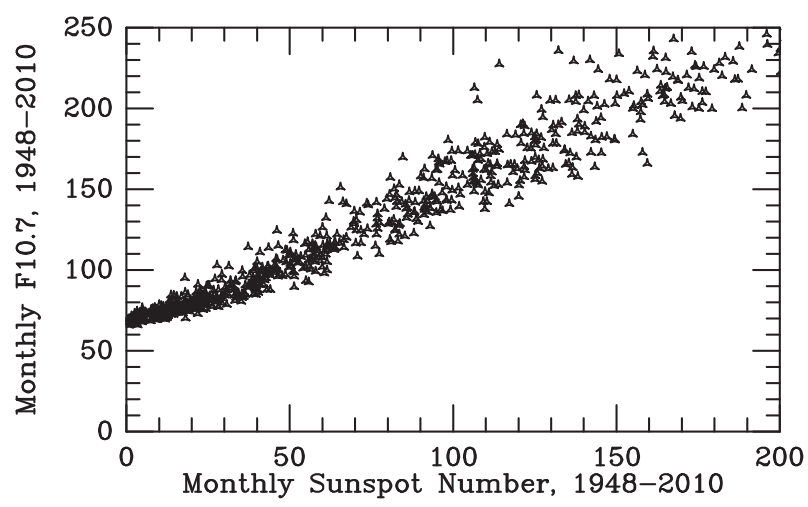

FIG. 9. Scatterplot of monthly mean solar $10.7 \mathrm{~cm}$ radio flux (sfu) vs monthly mean sunspot number over the $1948-2010$ period. See the text.

the applied solar forcing for the full simulations 1,2 , and 3 , respectively. Each simulation is 176 model years after discarding the first $55 \mathrm{yr}$ and consists of model years 56 through 231. For all three simulations, the mean responses in the Northern Hemisphere are generally weaker and less statistically significant than those obtained from the observations in Fig. 4, even though the model data record is $46 \mathrm{yr}$ longer than the observational record. This implies a somewhat weaker solar-induced response relative to internal climate variability in the model as compared to the observations (see, e.g., Kodera et al. 2003).

In the case of simulation 1 (Fig. 10), which assumed an ozone variation estimated using a $2 \mathrm{D}$ radiativephotochemical model, there is little or no resemblance of the time-averaged model solar response anomalies to the observational results. There is no positive SLP response anomaly in the North Pacific; instead a weak negative anomaly is present in the vicinity of the Aleutians. Also, the SLP response in the Arctic is positive so the overall $\mathrm{S} 1$ response is more consistent with a negative $\mathrm{AO}$ mode rather than a positive $\mathrm{AO}$ mode as was obtained in Fig. 4a. In the case of simulation 2 (Fig. 11), which assumed an ozone variation estimated from observations at latitudes $<60^{\circ}$, decreasing to zero at the poles, the SLP response is characterized by a moderate positive anomaly in the North Pacific and statistically insignificant negative responses over the Arctic. It is, therefore, more consistent with a positive AO mode as was obtained in Fig. 4a. In addition, a positive SST anomaly is detected in the midlatitude North Pacific, similar to that in Fig. $4 \mathrm{~b}$ except that it is most significant on the eastern side. In the case of simulation 3 (Fig. 12), which assumed an ozone variation estimated from observations at latitudes $<60^{\circ}$ and an ozone variation estimated from the $2 \mathrm{D}$ model at higher latitudes, there is again little resemblance of the model solar SLP and SST responses to those estimated observationally. The response is not (a) Simulation 1 DJF SLP Change per 130 Units F10.7 (56-231)

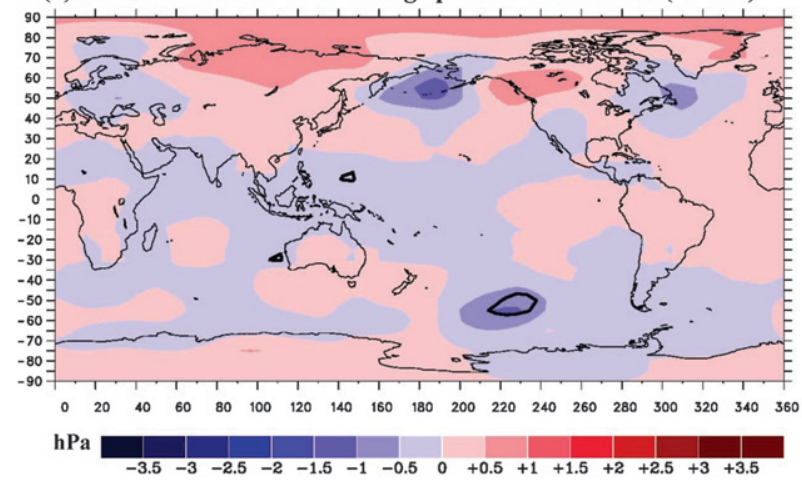

(b) Simulation 1 DJF SST Change per 130 Units F10.7 (56-231)

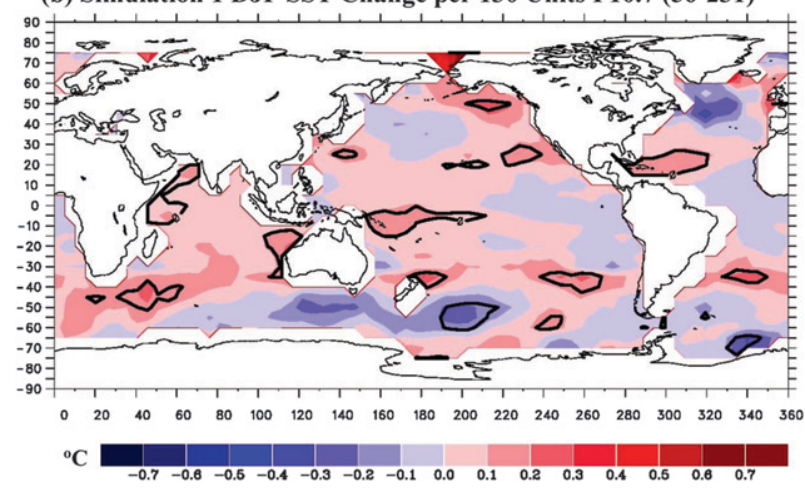

FIG. 10. Northern winter (a) mean sea level pressure and (b) sea surface temperature responses to a change of +130 units of the $10.7-\mathrm{cm}$ radio flux (F10.7). The responses are estimated from a multiple regression analysis of EGMAM simulation 1 (176 yr), which assumed a solar cycle ozone variation based on a 2D model calculation (Fig. 7a).

clearly positive or negative AO-like and there is a weak negative SLP response centered over Alaska.

As reviewed in the introduction, Bal et al. (2011) found stronger solar SLP and SST responses during some centennial periods of each simulation than when the entire 176-yr simulations were analyzed. Each simulation was therefore divided into six 105-yr overlapping segments (model years 56-160, 70-174, etc.) and the regression model was rerun on each segment. In the case of simulation 1, it was found that no 105-yr segment yielded a DJF response that was consistent with that derived from observations. However, some centennial periods yielded more significant responses in the North Pacific region than others. For example, when only the 112-216 model year period was analyzed, the North Pacific negative SLP response anomaly was stronger but the overall pattern (negative AO-like) remained inconsistent with that obtained in Fig. 4a. Similarly, the model solar SST response for this period in the North Pacific was unlike that in Fig. $4 b$.

In the case of simulation 2, it was also found that some centennial periods yielded more significant responses 
(a) Simulation 2 DJF SLP Change per 130 Units F10.7 (56-231)

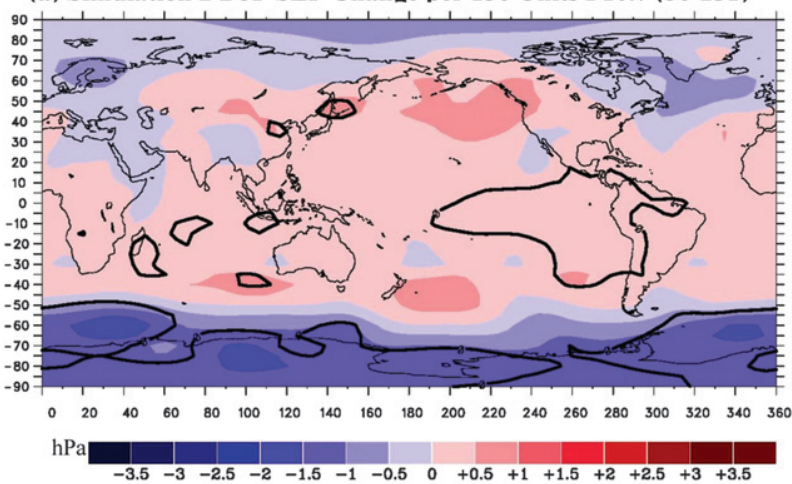

(b) Simulation 2 DJF SST Change per 130 Units F10.7 (56-231)

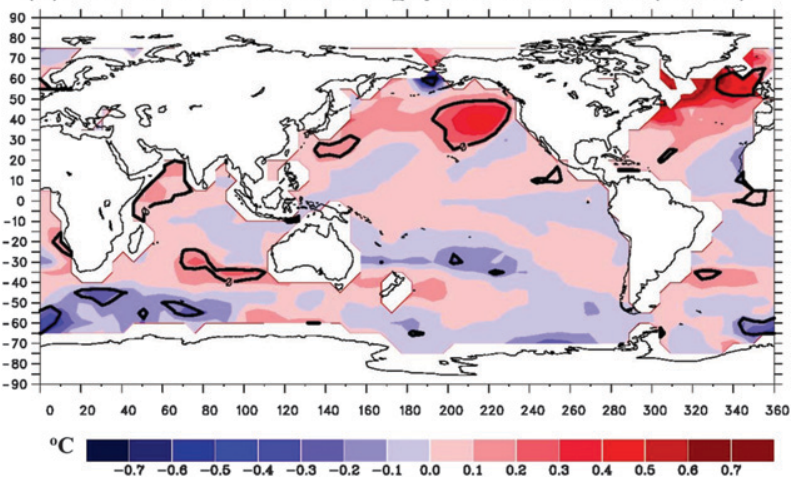

FIG. 11. As in Fig. 10, but based on a multiple regression analysis of EGMAM simulation 2 (176 yr), which assumed a solar cycle ozone variation based on observations (Fig. 7b).

in the North Pacific region. In particular, as shown in Fig. 13, the DJF model solar SLP and SST responses during the 70-174 model year period were found to be strongest and statistically significant, resembling those obtained observationally in the North Pacific region. Specifically, there is a strong positive SLP response anomaly in the Gulf of Alaska region and a corresponding positive SST response anomaly extending across the midlatitude North Pacific, similar to the observational results of Fig. 4. Like the model ENSO SLP response anomaly in the North Pacific shown in Fig. 8a, the solar SLP response anomaly is displaced somewhat to the southeast of its observational counterpart [i.e., it is centered southeast of the Aleutians (near $40^{\circ} \mathrm{N}, 140^{\circ} \mathrm{W}$ ) rather than directly over the Aleutians]. There is no significant negative SLP anomaly in the subtropics in Fig. 13, unlike in Fig. 4a. The reason why the responses are strongest during this selected part of simulation 2 is unknown but may be due to more internal model climate variability outside of this period.

In the case of simulation 3, it was again found that no centennial period yielded SLP and SST responses that resembled those obtained observationally. One centennial period (coincidentally also years 112-216) yielded (a) Simulation 3 DJF SLP Change per 130 Units F10.7 (56-231)

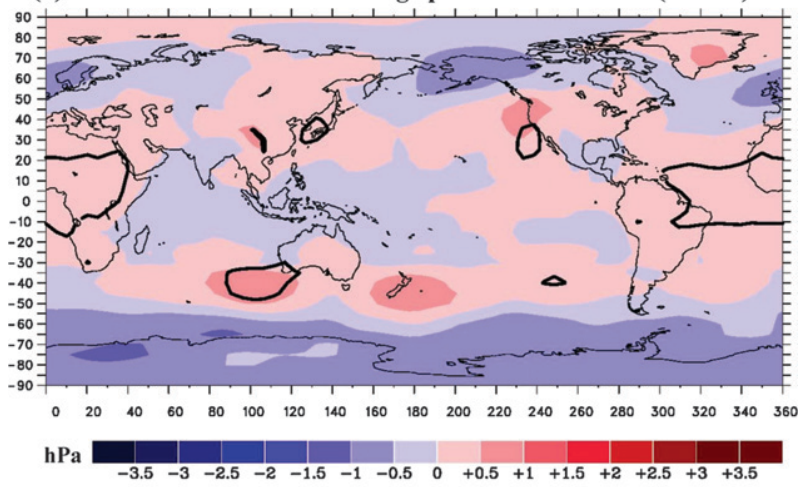

(b) Simulation 3 DJF SST Change per 130 Units F10.7 (56-231)

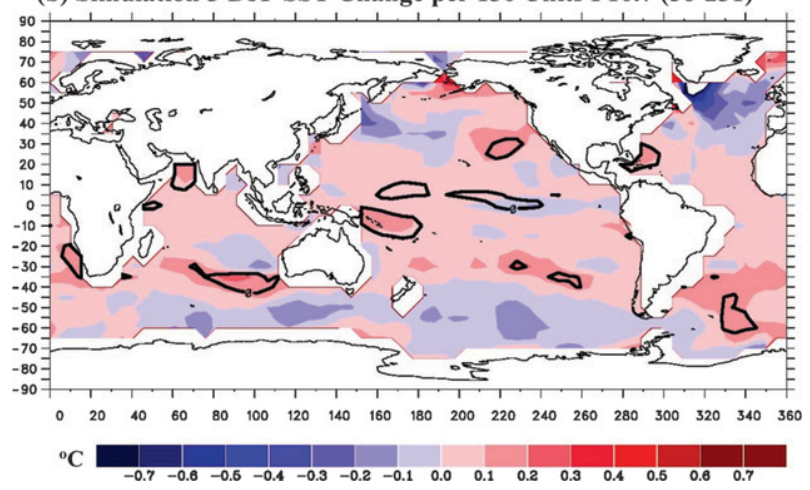

FIG. 12. As in Figs. 10 and 11, but based on a multiple regression analysis of EGMAM simulation 3 (176 yr), which assumed a solar cycle ozone variation based on observations at latitudes $<60^{\circ}$ and on 2D model calculations at higher latitudes (Fig. 7c).

the strongest and most significant signals. However, a significant negative SLP response anomaly was obtained over Alaska while a much weaker positive anomaly was obtained centered west of the northwestern U.S. coast. The SST response for this centennial period was also inconsistent with that obtained observationally in the Pacific sector.

The results of the EGMAM model simulations obtained here using an MLR method differ somewhat from those obtained by Bal et al. (2011) using a CMD method. Since the main difference between the MLR and CMD methods is that ENSO variability is accounted for to first order in the MLR model in (1), some aliasing from ENSO events could have affected the CMD results. For example, Bal et al. obtained a stronger model positive SLP response anomaly centered over the northeastern Pacific for a centennial period in simulation 1 (see their Fig. 2f) rather than in simulation 2 (Fig. 13a). Also, a more La Niña-like model SST response was obtained with a distinct negative ("cold tongue") response in the eastern equatorial Pacific (see their Figs. 2c,e). The absence of a distinct and statistically significant negative equatorial Pacific SST response in the MLR results of 
(a) Simulation 2 DJF SLP Change per 130 Units F10.7 (70-174)

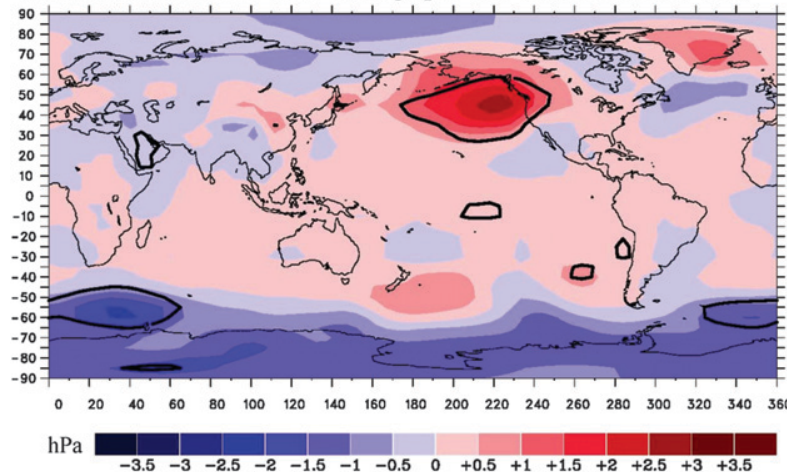

(b) Simulation 2 DJF SST Change per 130 Units F10.7 (70-174)

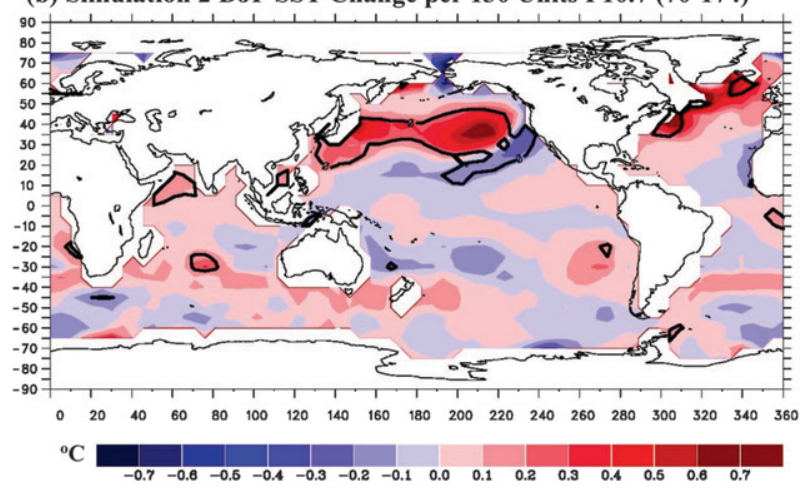

FIG. 13. As in Figs. 10-12, but for a selected centennial period of simulation 2 (105 yr).

Figs. 10b-13b suggests that the MLR method was better able to minimize such interference. If so, then the need to carefully minimize any possible aliasing from ENSO (e.g., by analyzing only relatively long time series using an MLR method) to more accurately estimate 11-yr solar signals in the Pacific sector is supported by these results (see also Haam and Tung 2012).

The model MLR results at zero lag in Figs. 10-13 so far indicate that simulation 2 yields the best overall agreement with the observational results of Fig. 4 in the Pacific sector, especially during a selected centennial period when the SLP and SST regression coefficients are strongest and most significant (Fig. 13). While this agreement is encouraging, it is also of interest to investigate whether the S2 model solar SLP and SST responses have a dependence on phase lag that resembles that obtained for the observational responses in Figs. 5 and 6. For this purpose, the MLR analyses for the 70-174 model year centennial period of simulation 2 were repeated at phase lags of -2 to $+2 \mathrm{yr}$ relative to solar maximum. Results are shown in Figs. 14 and 15 for the SLP and SST responses, respectively.

As seen in Fig. 14, the overall lagged model SLP response during this centennial period evolves from being positive AO-like several years before solar maximum to being negative AO-like several years after solar maximum in qualitative agreement with the lagged responses of Fig. 5. Specifically, for both the observed and model SLP responses, the "Aleutian" positive response anomaly evolves from being relatively weak at a lag of -2 years to reaching maximum amplitude at 0 -yr lag and declines thereafter, although the decline is slower for the model response. Also, in both cases, the Arctic response, although statistically insignificant, evolves from being clearly positive a few years before solar maximum to being negative at and following solar maximum. The agreement is generally better in the Pacific sector than in the Atlantic sector where a strong negative NAO mode is seen prior to solar maximum in the observations but not clearly in the model simulation.

As seen in Fig. 15, the overall model lagged positive SST response in the midlatitude North Pacific is smaller in area at a lag of -2 years, reaches a maximum amplitude and areal extent at 0-yr lag (Fig. 13b) and then separates into relatively small maxima at a lag of $+2 \mathrm{yr}$. There is no distinct equatorial eastern Pacific negative response at any phase lag, unlike the observations, which show a weak but significant eastern equatorial Pacific response, especially at zero lag (Fig. 4b). The cooling response in the Labrador Sea seen in the observations especially at positive lags (Fig. 6) is not seen in the model simulations. This is consistent with the absence of a positive SLP response over eastern North America that is obtained in the observational analyses of Figs. 4a and 5, but not in the model simulation results of Figs. 13a and 14.

\section{Discussion and conclusions}

The observational analyses of section 2 provide additional evidence that a surface climate response to $11-\mathrm{yr}$ solar forcing during the boreal winter season is detectable in global SLP and SST records extending back to the nineteenth century. The response is most clearly detected in the Pacific sector where a positive solar SLP response anomaly is obtained over the Aleutian region and a corresponding positive SST response anomaly extends across the midlatitude North Pacific (Fig. 4). The SLP response in the Arctic is generally negative supporting the hypothesis that the solar response is similar to a positive Arctic Oscillation mode. However, only a weak and marginally significant SST response is obtained in the equatorial eastern Pacific so the response differs from that which characterizes a La Niña event (see also van Loon and Meehl 2008). Analyses of the observed response as a function of phase lag indicate that the solar SLP response evolves from a predominately negative AO structure a few years prior to solar maximum to a predominately positive AO structure at and following solar maximum (Fig. 5). The amplitudes of the Aleutian SLP 


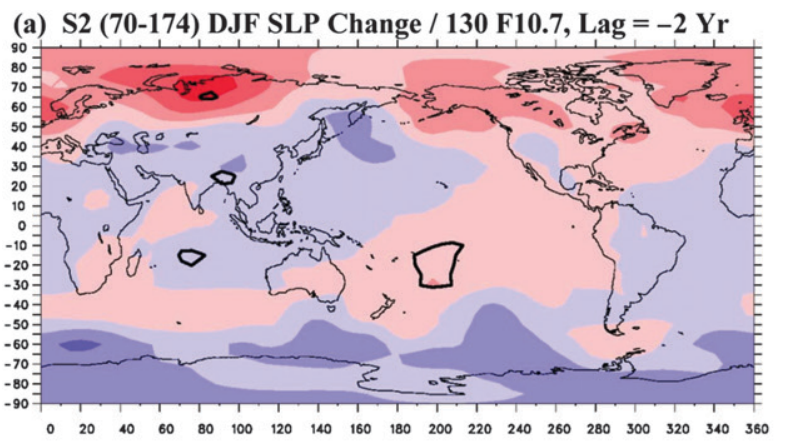

(b) S2 (70-174) DJF SLP Change / 130 F10.7, Lag = -1 Yr

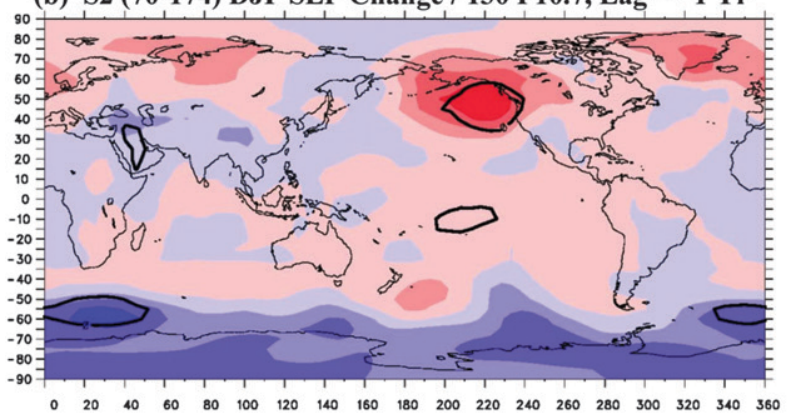

(c) S2 (70-174) DJF SLP Change / 130 F10.7, Lag $=+1$ Yr

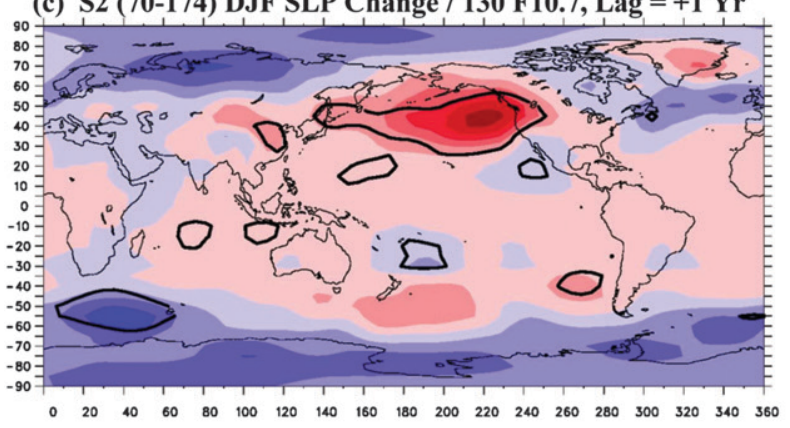

(d) S2 (70-174) DJF SLP Change / 130 F10.7, Lag $=+2$ Yr

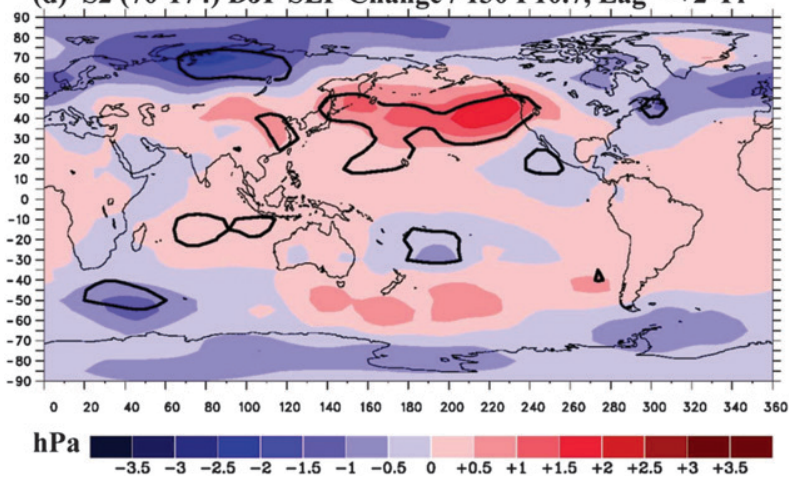

FIG. 14. The northern winter SLP response to a change in F10.7 of +130 during the selected centennial period of EGMAM simulation 2 as a function of phase lag (format as in Fig. 13a): (a) 2 and (b) $1 \mathrm{yr}$ before solar maximum; and (c) 1 and (d) $2 \mathrm{yr}$ after solar maximum.

response anomaly and the corresponding positive SST anomaly maximize at zero lag.

In general, models should be validated by observations rather than the other way around. However, it (a) S2 (70-174) DJF SST Change / 130 F10.7, Lag $=-2 \mathrm{Yr}$

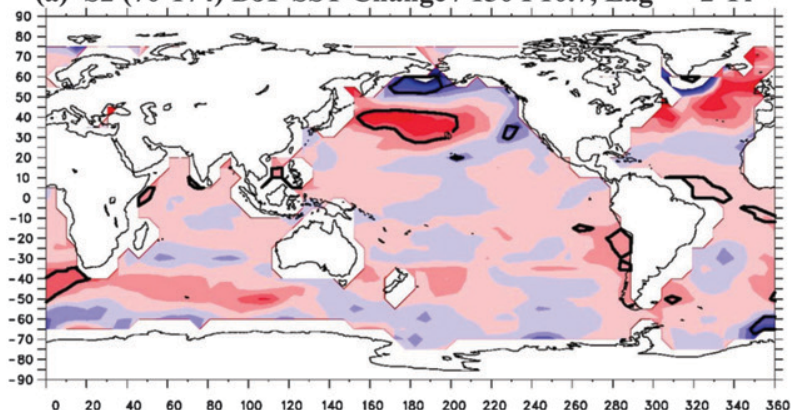

(b) S2 (70-174) DJF SST Change / 130 F10.7, Lag = -1 Yr

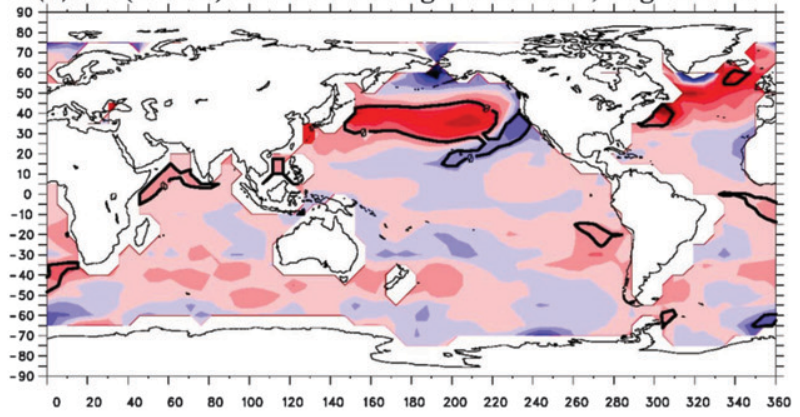

(c) S2 (70-174) DJF SST Change / 130 F10.7, Lag = +1 Yr

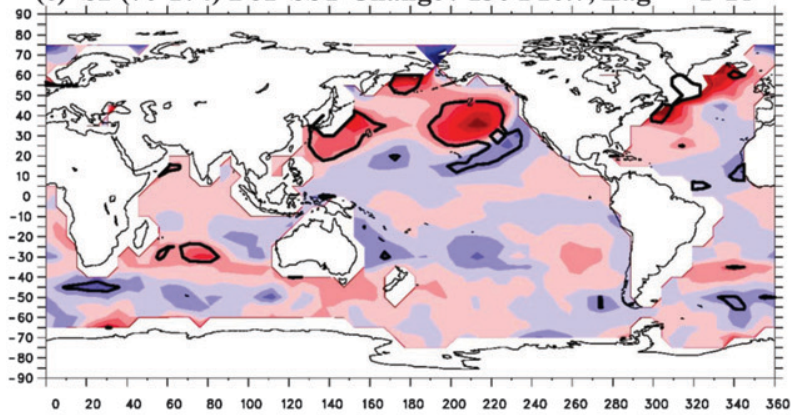

(d) S2 (70-174) DJF SST Change / 130 F10.7, Lag $=+2$ Yr

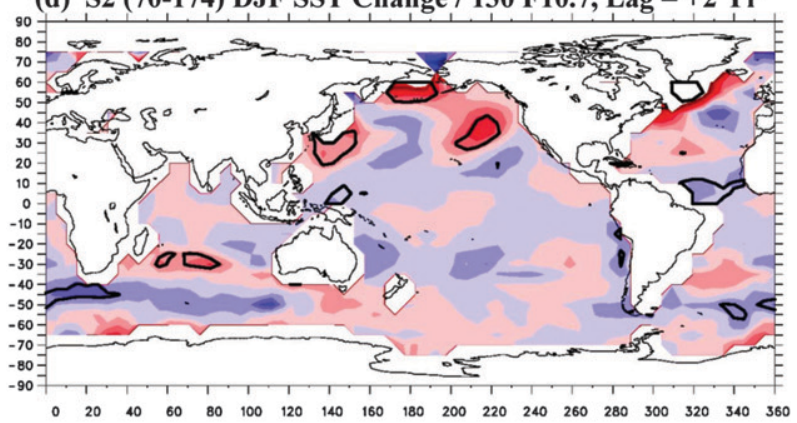

hPa

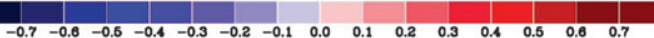

FIG. 15. As in Fig. 14, but for SST.

greatly strengthens an observational result if the physical processes that lead to that result are understood. The latter can only be accomplished using models. Here, we have carried out initial comparisons with EGMAM simulation results as a step toward testing our understanding 
of those physical processes, particularly whether the topdown forcing mechanism could be responsible for the observed surface climate response during northern winter. The model MLR analyses of section 3 provide provisional evidence that the simulated surface climate response to 11-yr solar forcing in boreal winter is sensitive to the imposed solar cycle variation of stratospheric ozone. Simulation 2, which assumed an ozone variation estimated from observational analyses at latitudes $<60^{\circ}$, decreasing linearly to zero at the poles, yields the best agreement with the observationally estimated solar response in the North Pacific region, especially for a selected centennial period. Specifically, the model response is also characterized by a positive SLP response anomaly in the northeast Pacific and a corresponding positive SST response extending across the midlatitude North Pacific (Fig. 13). Analyses of the model SLP and SST responses as a function of phase lag during the selected centennial period of simulation 2 show that the model SLP response also evolves from a predominately negative AO-like structure a few years before solar maximum to a positive AO-like structure (except in the Atlantic sector) at and following solar maximum (Fig. 14). The model positive SLP response anomaly in the northeast Pacific and the corresponding positive SST response anomaly across the midlatitude North Pacific maximize near zero lag as is also seen in the observational results.

Overall, the similarity of the model-generated SLP and SST responses in the North Pacific with those estimated from observations, including the dependence on phase lag, suggests that the observed responses in this region are more likely to be real than a consequence of a coincidental alignment of ENSO events with the solar cycle during the 130-yr observation period. On the other hand, many of the apparently significant positive and negative SST response anomalies in the subtropical and tropical Pacific obtained from the observational analysis (Fig. 4b) are not replicated in the model simulation. The same is true of the positive SLP response anomaly in eastern North America shown in Fig. 4a. Consequently, these results must be regarded as provisional and further model simulations (preferably an ensemble of realizations for a series of assumed solar cycle ozone variations) are needed before final conclusions can be drawn.

Nevertheless, the sensitivity of the model results analyzed so far to the applied stratospheric ozone solar cycle variation supports the hypothesis that top-down forcing is important in determining the model surface climate response. Since the most successful ozone solar cycle variation (that applied in simulation 2) is the one that is most consistent with observational analyses of satellite ozone data, these results suggest that it is important for a model to simulate a realistic ozone variation to produce a realistic 11 -yr surface climate response. A similar conclusion was drawn by Haigh (1999) in a study of GCM simulations of tropospheric climate forced with 2D model and observationally estimated solar cycle ozone variations. In particular, the ozone variation applied in simulation 2 is characterized by a larger solar cycle change in the upper stratosphere than is estimated in many models, including 3D models as well as 2D models (e.g., Marsh et al. 2007; Austin et al. 2008; Chiodo et al. 2012). This, combined with the assumed linear decrease to zero from $60^{\circ}$ latitude to the poles, yields a relatively strong latitudinal gradient in radiative heating in the upper stratosphere that would produce a corresponding strong thermal wind perturbation in early winter. Since this zonal wind anomaly under solar maximum conditions is believed to be the main initiator of the top-down mechanism (e.g., Kodera and Kuroda 2002), this could explain why simulation 2 yielded the best agreement with the observationally derived surface response in the Pacific sector.

The results of the present analyses, including the positive AO-like character of the observationally and model-estimated solar SLP and SST responses during northern winter at zero and positive lags as well as the likely production of a strong zonal wind anomaly near solar maxima in the upper stratosphere in the most successful model simulation, are consistent with expectations based on previous studies of stratospheric forcing of surface climate change. For example, Yukimoto and Kodera (2007) found that imposing a westerly momentum forcing in the winter midlatitude stratosphere in an atmosphere-ocean GCM yields a spatial structure for the atmospheric response that resembles a positive phase of the northern annular mode (NAM). At the surface, the latter reduces to a positive phase of the Arctic Oscillation. A positive SLP response anomaly centered over the eastern North Pacific was simulated as well as a corresponding positive SST anomaly over the midlatitude North Pacific and a negative SST anomaly centered over the Gulf of Alaska (see their Figs. 2 and 3 ). The authors also investigated oceanic feedback on the atmospheric response using an atmospheric model forced by the model-induced SST change and found that positive feedbacks of the oceanic response on the NAM-like atmospheric response were likely. These previous GCM experiments for generalized stratospheric forcing as well as the EGMAM simulation 2 results reported here for a realistic solar and ozone forcing experiment therefore support the hypothesis that top-down forcing is mainly responsible for the observationally estimated surface climate response to 11-yr solar forcing during northern winter. However, further 
analyses of stratospheric and tropospheric model data (including EGMAM model data) as well as further analyses of corresponding stratospheric and tropospheric observations are needed to complement the surface climate results reported here and confirm this provisional conclusion.

Acknowledgments. This work was supported under Grant AGS-1067827 from the Climate Dynamics Branch of the U.S. National Science Foundation and under Grant NNX10AQ63G from the NASA Living With a Star Targeted Research and Technology Program. Hadley Centre SLP and SST data were obtained from the Met Office Hadley Centre Observations website (www. metoffice.gov.uk). Stefan Brönnimann kindly provided reconstructed N3.4 time series covering the 1880-2009 period, as was needed for the observational SLP and SST analyses. Thanks to Boris Soukharev for his important assistance with MLR software development. One of us (LLH) thanks K. Kodera, L. Gray, and G. Meehl for helpful discussions at the HEPPA/SOLARIS workshop held in October 2012 at Boulder, Colorado. We also thank the two reviewers for useful criticisms.

\section{REFERENCES}

Allan, R., and T. Ansell, 2006: A new globally complete monthly historical gridded mean sea level pressure dataset (HadSLP2): 1850-2004. J. Climate, 19, 5816-5842.

Austin, J., and Coauthors, 2008: Coupled chemistry climate model simulations of the solar cycle in ozone and temperature J. Geophys. Res., 113, D11306, doi:10.1029/2007JD009391.

Bal, S., S. Schimanke, T. Spangehl, and U. Cubasch, 2011: On the robustness of the solar cycle signal in the Pacific region. Geophys. Res. Lett., 38, L14809, doi:10.1029/2011GL047964.

Chiodo, G., N. Calvo, D. R. Marsh, and R. Garcia-Herrera, 2012: The 11 year solar cycle signal in transient simulations from the Whole Atmosphere Community Climate Model. J. Geophys. Res., 117, D06109, doi:10.1029/2011JD016393.

Christoforou, P., and S. Hameed, 1997: Solar cycle and the Pacific “centers of action." Geophys. Res. Lett., 24, 293-296.

Cochrane, D., and G. H. Orcutt, 1949: Application of least squares regression to relationships containing autocorrelated error terms. J. Amer. Stat. Assoc., 44, 32-61.

Crooks, S. A., and L. J. Gray, 2005: Characterization of the 11-year solar signal using a multiple regression analysis of the ERA-40 dataset. J. Climate, 18, 996-1015.

DeLand, M. T., and R. P. Cebula, 2012: Solar UV variations during the decline of cycle 23. J. Atmos. Sol.-Terr. Phys., 77, 225-234.

Fortuin, J. P., and U. Langematz, 1994: An update on the global ozone climatology and on concurrent ozone and temperature trends. Atmospheric Sensing and Modelling, R. P. Santer, Ed., International Society for Optical Engineering (SPIE Proceedings, Vol. 2311), 207-216.

Frame, T. H. A., and L. J. Gray, 2010: The 11-year solar cycle in ERA-40 data: An update to 2008. J. Climate, 23, 2213-2222.

Garny, H., G. E. Bodeker, and M. Dameris, 2007: Trends and variability in stratospheric mixing: 1979-2005. Atmos. Chem. Phys., 7, 5611-5624.
Gray, L. J., S. T. Rumbold, and K. P. Shine, 2009: Stratospheric temperature and radiative forcing response to 11-year solar cycle changes in irradiance and ozone. J. Atmos. Sci., 66, 24022417.

, and Coauthors, 2010: Solar influences on climate. Rev. Geophys., 48, RG4001, doi:10.1029/2009RG000282.

Haam, E., and K.-K. Tung, 2012: Statistics of solar cycle-La Niña connection: Correlation of two autocorrelated time series. J. Atmos. Sci., 69, 2934-2939.

Haigh, J. D., 1996: On the impact of solar variability on climate. Science, 272, 981-984.

_ 1999: A GCM study of climate change in response to the 11-year solar cycle. Quart. J. Roy. Meteor. Soc., 125, 871-892, doi:10.1002/qj.4971255506.

- M. Blackburn, and R. Day, 2005: The response of tropospheric circulation to perturbations in lower stratospheric temperature. J. Climate, 18, 3672-3691.

Harder, J. W., J. M. Fontenla, P. Pilewskie, E. C. Richard, and T. N. Woods, 2009: Trends in solar spectral irradiance variability in the visible and infrared. Geophys. Res. Lett., 36, L07801, doi:10.1029/2008GL036797.

Hartmann, D. L., 1994: Global Physical Climatology. Academic Press, $411 \mathrm{pp}$.

Hood, L. L., and B. E. Soukharev, 2006: Solar induced variations of odd nitrogen: Multiple regression analysis of UARS HALOE data. Geophys. Res. Lett., 33, L22805, doi:10.1029/ 2006GL028122.

— , and —, 2012: The lower stratospheric response to 11-yr solar forcing: Coupling to the troposphere-ocean response. J. Atmos. Sci., 69, 1841-1863.

_ J. L. Jirikowic, and J. P. McCormack, 1993: Quasi-decadal variability of the stratosphere: Influence of long-term solar ultraviolet variations. J. Atmos. Sci., 50, 3941-3958.

_ B. E. Soukharev, and J. P. McCormack, 2010: Decadal variability of the tropical stratosphere: Secondary influence of the El Niño-Southern Oscillation. J. Geophys. Res., 115, D11113, doi:10.1029/2009JD012291.

Ineson, S., A. Scaife, J. Knight, J. Manners, N. Dunstone, L. Gray, and J. Haigh, 2011: Solar forcing of winter climate variability in the Northern Hemisphere. Nat. Geosci., 4, 753-757, doi:10.1038/ngeo1282.

Jackman, C. H., D. R. Marsh, F. M. Vitt, R. R. Garcia, C. E. Randall, E. L. Fleming, and S. M. Frith, 2009: Long-term middle atmospheric influence of very large solar proton events. J. Geophys. Res., 114, D11304, doi:10.1029/2008JD011415.

James, I. N., 1995: Introduction to Circulating Atmospheres. Cambridge University Press, 448 pp.

Kodera, K., and K. Yamazaki, 1990: Long-term variation of upper stratospheric circulation in the Northern Hemisphere in December. J. Meteor. Soc. Japan, 68, 101-105. , and Y. Kuroda, 2002: Dynamical response to the solar cycle: Winter stratopause and lower stratosphere. J. Geophys. Res., 107, 4749, doi:10.1029/2002JD002224.

_ K. Katthes, K. Shibata, U. Langematz, and Y. Kuroda, 2003: Solar impact on the lower mesospheric subtropical jet: A comparative study with general circulation model simulations. Geophys. Res. Lett., 30, 1315, doi:10.1029/2002GL016124.

Lau, K., P. Shen, and I. Kang, 1994: Multiscale low-frequency circulation modes in the global atmosphere. J. Atmos. Sci., 51, 1169-1193.

Lean, J., 2000: A decadal solar effect in the evolution of the Sun's spectral irradiance since the Maunder Minimum. Geophys. Res. Lett., 27, 2425-2428. 
— and M. T. DeLand, 2012: How does the Sun's spectrum vary? J. Climate, 25, 2555-2560.

- J. Beer, and R. Bradley, 1995: Reconstruction of solar irradiance since 1610: Implications for climate change. Geophys. Res. Lett., 22, 3195-3198.

Legutke, S., and R. Voss, 1999: The Hamburg Atmosphere-Ocean Coupled Circulation Model ECHO-G. Tech. Rep. 18, Deutsche Klimarechenzentrum, Hamburg, Germany, 70 pp.

Mantua, N. J., S. R. Hare, Y. Zhang, J. M. Wallace, and R. C. Francis, 1997: A Pacific interdecadal climate oscillation with impacts on salmon production. Bull. Amer. Meteor. Soc., 78, 1069-1079.

Manzini, E., and N. A. McFarlane, 1998: The effect of varying the source spectrum of a gravity wave parameterization in a middle atmosphere general circulation model. J. Geophys. Res., 103 (D24), 31 523-31539.

Marsh, D. R., R. Garcia, D. Kinnison, B. Boville, F. Sassi, S. C. Solomon, and K. Matthes, 2007: Modeling the whole atmosphere response to solar cycle changes in radiative and geomagnetic forcing. J. Geophys. Res., 112, D23306, doi:10.1029/ 2006JD008306.

Matthes, K., Y. Kuroda, K. Kodera, and U. Langematz, 2006: Transfer of the solar signal from the stratosphere to the troposphere: Northern winter. J. Geophys. Res., 111, D06108, doi:10.1029/2005JD006283.

Meehl, G. A., J. M. Arblaster, G. Branstator, and H. van Loon, 2008: A coupled air-sea response mechanism to solar forcing in the Pacific region. J. Climate, 21, 2883-2897.

- — - K. Matthes, F. Sassi, and H. van Loon, 2009: Amplifying the Pacific climate system response to a small 11-year solar cycle forcing. Science, 325, 1114-1118.

Misios, S., and H. Schmidt, 2012: Mechanisms involved in the amplification of the 11-yr solar cycle signal in the tropical Pacific ocean. J. Climate, 25, 5102-5118.

Nissen, K., K. Matthes, U. Langematz, and B. Mayer, 2007: Towards a better representation of the solar cycle in general circulation models. Atmos. Chem. Phys., 7, 5391-5400.

Randall, C. E., V. L. Harvey, D. E. Siskind, J. France, P. F. Bernath, C. D. Boone, and K. A. Walker, 2009: $\mathrm{NO}_{\mathrm{X}}$ descent in the Arctic middle atmosphere in early 2009. Geophys. Res. Lett., 36, L18811, doi:10.1029/2009GL039706.

Randel, W. J., and F. Wu, 2007: A stratospheric ozone profile data set for 1979-2005: Variability, trends, and comparisons with column ozone data. J. Geophys. Res., 112, D06313, doi:10.1029/ 2006JD007339.

Rayner, N. A., D. E. Parker, E. B. Horton, C. K. Folland, L. V. Alexander, D. P. Rowell, E. C. Kent, and A. Kaplan, 2003: Global analyses of sea surface temperature, sea ice, and night marine air temperature since the late nineteenth century. J. Geophys. Res., 108, 4407, doi:10.1029/2002JD002670.

, P. Brohan, D. E. Parker, C. K. Folland, J. J. Kennedy, M. Vanicek, T. J. Ansell, and S. F. B. Tett, 2006: Improved analyses of changes and uncertainties in sea surface temperature measured in situ since the mid-nineteenth century: The HadSST2 dataset. J. Climate, 19, 446-469.

Reinsel, G. C., A. J. Miller, E. C. Weatherhead, L. E. Flynn, R. M. Nagatani, G. C. Tiao, and D. J. Wuebbles, 2005: Trend analysis of total ozone data for turnaround and dynamical contributions. J. Geophys. Res., 110, D16306, doi:10.1029/ 2004JD004662.

Roy, I., and J. Haigh, 2010: Solar cycle signals in sea level pressure and sea surface temperatures. Atmos. Chem. Phys., 10, 3147-3153.
— and - 2012: Solar cycle signals in the Pacific and the issue of timings. J. Atmos. Sci., 69, 1446-1451.

Schmidt, H., G. P. Brasseur, and M. A. Giorgetta, 2010: Solar cycle signal in a general circulation and chemistry model with internally generated quasi-biennial oscillation. J. Geophys. Res., 115, D00114, doi:10.1029/2009JD012542.

Simpson, I., M. Blackburn, and J. D. Haigh, 2009: The role of eddies in driving the tropospheric response to stratospheric heating perturbations. J. Atmos. Sci., 66, 1347-1365.

Smith, T. M., and R. W. Reynolds, 2003: Extended reconstruction of global sea surface temperatures based on COADS data (1854-1997). J. Climate, 16, 1495-1510.

$\longrightarrow$, and -2004 : Improved extended reconstruction of SST (1854-1997). J. Climate, 18, 2021-2036.

$\longrightarrow, \ldots$, T. C. Peterson, and J. Lawrimore, 2008: Improvements to NOAA's historical merged land-ocean surface temperature analysis (1880-2006). J. Climate, 21, 2283-2296.

Soukharev, B. E., and L. Hood, 2006: Solar cycle variation of stratospheric ozone: Multiple regression analysis of long-term satellite data sets and comparisons with models. J. Geophys. Res., 111, D20314, doi:10.1029/2006JD007107.

Thompson, D. W. J., and J. M. Wallace, 1998: The Arctic Oscillation signature in the wintertime geopotential height and temperature fields. Geophys. Res. Lett., 25, 1297-1300.

_ , J. J. Kennedy, J. M. Wallace, and P. D. Jones, 2008: A large discontinuity in the mid-twentieth century in observed global mean surface temperature. Nature, 453, 646-649, doi:10.1038/ nature06982.

Tiao, G., and Coauthors, 1990: Effects of autocorrelation and temporal sampling schemes on estimates of trend and spatial correlation. J. Geophys. Res., 95 (D12), 20 507-20517.

Tung, K.-K., and J. Zhou, 2010: The Pacific's response to surface heating in $130 \mathrm{yr}$ of SST: La Niña-like or El Niño-like? J. Atmos. Sci., 67, 2649-2657.

van Loon, H., and G. A. Meehl, 2008: The response in the Pacific to the Sun's decadal peaks and contrasts to cold events in the Southern Oscillation. J. Atmos. Sol.-Terr. Phys., 70, 10461055 .

— G. Meehl, and D. Shea, 2007: Coupled air-sea response to solar forcing in the Pacific region during northern winter. J. Geophys. Res., 112, D02108, doi:10.1029/2006JD007378.

von Storch, H., and F. W. Zwiers, 2002: Statistical Analysis in Climate Research. Cambridge University Press, 494 pp.

Wallace, J. M., and D. S. Gutzler, 1981: Teleconnections in the geopotential height field during the Northern Hemisphere winter. Mon. Wea. Rev., 109, 784-812.

Wang, Y.-M., J. Lean, and N. R. Sheeley Jr., 2005: Modeling the sun's magnetic field and irradiance since 1713. Astrophys. J., $\mathbf{6 2 5}, 522-538$.

White, W. B., and Z. Liu, 2008: Resonant excitation of the quasidecadal oscillation by the 11-yr signal in the Sun's irradiance. J. Geophys. Res., 113, C01002, doi:10.1029/2006JC004057.

_ J J. Lean, D. R. Cayan, and M. D. Dettinger, 1997: Response of global upper ocean temperature to changing solar irradiance. J. Geophys. Res., 102 (C2), 3255-3266.

Yukimoto, S., and K. Kodera, 2007: Annular modes forced from the stratosphere and interactions with the oceans. J. Meteor. Soc. Japan, 85, 943-952.

Zhang, Y., J. M. Wallace, and D. S. Battisti, 1997: ENSO-like interdecadal variability: 1900-93. J. Climate, 10, 1004-1020.

Zhou, J., and K.-K. Tung, 2010: Solar cycles in 150 years of global sea surface temperature data. J. Climate, 23, 3234-3248. 